\title{
A Network-Based Approach to Study Returns Synchronization of Stocks: The Case of Global Equity Markets
}

\author{
Jaime F. Lavin $\mathbb{D}^{1},{ }^{1}$ Mauricio A. Valle $\mathbb{D}^{\circ},{ }^{2}$ and Nicolás S. Magner $\mathbb{D}^{3}$ \\ ${ }^{1}$ Business School, Universidad Adolfo Ibáñez, Santiago, Chile \\ ${ }^{2}$ Faculty of Economics and Business, Universidad Finis Terrae, Santiago, Chile \\ ${ }^{3}$ Facultad de Economía y Empresa, Universidad Diego Portales, Santiago, Chile \\ Correspondence should be addressed to Jaime F. Lavin; jaime.lavin@uai.cl
}

Received 12 May 2021; Accepted 14 September 2021; Published 9 November 2021

Academic Editor: Baogui Xin

Copyright (C) 2021 Jaime F. Lavin et al. This is an open access article distributed under the Creative Commons Attribution License, which permits unrestricted use, distribution, and reproduction in any medium, provided the original work is properly cited.

The synchronization in financial markets has increased during the rise of global markets. Nevertheless, global shocks provoke high levels of returns synchronization that jeopardize market stability. Using correlation-based networks, regressions, and VAR models, we measure and estimate the effect of global synchronization on the world equity markets of North America, Latin America, Europe, Asia, and Oceania between July 2001 and April 2020. We find that our measure of global stock synchronization is dynamic over time, its minimums coincide with significant financial shocks, and it shrinks to its minimum levels, indicating that the returns of global markets are moving in a synchronized way. Also, it is a significant and positive factor of regional synchronization. Regional markets react heterogeneously to global synchronization shocks suggesting both local and global factors are sources of synchronization. Our work helps market participants who need to measure, monitor, and manage the synchronization of returns in a parsimonious, dynamic, and empirically tractable way. Our evidence highlights the necessity of including synchronization as a risk factor to assess the decision-making criteria of a broad range of market participants ranging from regulators to investors. To policy-makers, governments, and central banks, our work is a call to incorporate events of high global synchronization into the radar of hazards of the whole market stability.

\section{Introduction}

During recent decades, we have witnessed the emergence of global financial markets. Greater economic openness and increasing integration fostered financial integration, a higher interconnectedness in capital markets, and a greater size and complexity of the financial systems. As a result, the global financial market becomes a "complex system" highly interconnected with cross-border interconnections and interdependencies, where shocks easily amplify and quickly turn into global events. Studies on interconnectedness show its dual impact on systemic risk; it could improve financial robustness when it contributes to absorbs shocks, but it could also generate contagion when propagates shocks among the components of a financial system [1-3].

During financial turbulences, risk appetite fades provoking that the liquidity of risky assets practically disappears, transforming them into a generalized herd-like behavior, where investors desperately seek risk-free assets to take refuge. (For example, between February 15 and March 23 of 2020, the world witnessed violent falls in the financial markets; the S\&P500 index accumulated falls of 35.33\%; and the reference price for WTI oil fell by $58.13 \%$, extending its fall to USD 17.27 during April. Likewise, during the same period, the interest rates of the 10-year bonds of the United States Treasury fell by $80.60 \%$, reaching an all-time minimum of $0.3137 \%$ annually.) These behaviors are similar among world financial markets, reflecting that uncertainty and volatility are ubiquitous characteristics of capital markets during global shocks. Moreover, this uncertainty regarding the future performance of financial markets is not novel for the market. As past episodes have shown, it changes the volatility of the returns of financial assets, risk management, and asset pricing, affecting consumption, savings, and investment decisions in 
the economy [4]. For instance, the COVID-19 outbreak turned into a global shock that simultaneously affected most of the world economies. From a financial stability perspective, this shock negatively impacted the valuations of financial assets such as stocks and bonds. In addition, it generated the well-known flight to quality and liquidity hoarding effects typically observed in global capital markets during past episodes of financial turmoil $[3,5]$.

The complex relationship between financial markets and their constituents and their connectedness patterns and structures attracted the attention of academics, regulators, and market practitioners for its effects on market risk, systemic risk, and business cycle risk. After the 2007-8 financial crisis, financial markets have been studied through networkbased models, focusing initially on the study of cascading effects on the financial sector $[2,5,6]$. Initial models depicted well how the structure of the financial network can lead to cascades of default under contagion and are capable of estimating the probability and impact of its occurrence. However, a deeper understanding and measuring of how shocks are amplified and propagated through financial networks of assets is still required. In this work, we study the phenomenon of equity markets returns' synchronization that especially emerges when the stock market is faced with sharp downtrends, causing that a large number of participants in the market suffer severe losses at the same time, a behavior that quickly propagates to the entire market [7]. This phenomenon was particularly present during the Subprime Crisis in 2008 and the initial stages of the COVID-19 outbreak in 2020.

Synchronization or co-movement of returns is a particularly relevant phenomenon in stock markets since contagion generates a significant change in market volatility and stock's correlation coefficients [8]. For a broader viewpoint [1], the synchronization of equity returns is critical to the financial system. In this sense, economic structural similarities of countries and regions, coupled with global factors, explain financial markets' co-movement and generate financial contagion on a large scale [9]. Moreover, evidence indicates that interconnections among financial markets vary over time, being an uneven phenomenon among countries and regions [10].

The Subprime Crisis revealed that networks of obligations, for instance, banks [11], or assets between financial agents, for example, mutual funds [12], are possible elements behind the co-movement of financial assets and the stability of financial markets. This phenomenon is crucial under the conditions such as a significant concentration of assets in a few financial institutions and during financial shocks. For instance, Lavin, Valle, and Magner [13] found that similarities in mutual funds' portfolio strategies become a potential factor of disturbance with implications on the stability of the network conformed by stocks and funds. This evidence suggests that synchronization of returns is a highly complex phenomenon with no single cause; on the contrary, as we witness during the past financial turmoil of the pandemic outbreak, its occurrence relates to multiple factors $[9,14,15]$.

We analyze the synchronization of returns from a regional and global market viewpoint. Our paper studies comovement and not integration because we focus on shedding light on how equity market correlations dynamically vary among periods of financial stability and instability. Historical financial turmoil episodes show that all these events share some structural properties and that not all markets react equally when global returns' co-movement skyrocket in terms of how the synchronization phenomenon evolves and spreads among global equity markets. The following research questions are not fully covered in how the synchronization phenomenon evolves and spreads among global equity markets. First, is it possible to gauge the aggregate level of synchronization of market returns? Second, how does global stock market synchronization affect regional markets? Third, do variations in the global stock market synchronization uniformly affect regional markets? And finally, does regional equity markets' synchronization typically move with or against the global equity markets' synchronization?

We contribute to the literature by studying this phenomenon in an appropriately parsimonious, dynamic, and empirically tractable way using correlation-based networks methods coupled with time-series analysis and VAR models. First, we tackle the previous research questions measuring the global synchronization of equity returns of 27 world equity markets indices from July 2001 to April 2020. Second, we build asset correlation trees of global and regional equity networks using planar filtering methods such as minimum spanning trees and Planar Maximally Filtered Graphs [16]. Third, we study the global synchronization effect on regional markets applying structural VAR and impulse-response function analysis. Fourth, exploring the dynamic quantification of the synchronization of returns at a broad market level, we help to monitor this phenomenon by estimating a global measure of synchronization that helps explain the regional co-movement of regional equity markets. Finally, we facilitate the task of monitoring synchronization risk by providing a sensitivity measure of each regional market to changes in the global market synchronization.

Specifically, we apply the length of the minimum spanning tree (MSTL) as a measure of synchronicity of returns for the regional markets (MSTLR) of North and Latin America, Europe, Asia, and Oceania. Similarly, we estimate the MSTL for the global equity market network (MSTLG) formed by the 27 equity markets that conform to the latter regional markets. After this, we organize our empirical strategy on three steps:

(1) We dynamically measure with MSTL the degree of synchronization at both regional (MSTLR) and global (MSTLG) levels.

(2) We econometrically test whether the global synchronization measure (MSTLG) is relevant in synchronizing regional markets (MSTLR) of North and Latin America, Europe, Asia, and Oceania.

(3) We empirically analyze whether global synchronization (MSTLG) levels affect the stock market's synchronization of the regional markets and contribute to generating future unequal synchronization among them. 
Our main results show that the global synchronization of stock returns measured by the MSTLG dynamically captures changes in the global equity correlation network structure, especially during calms and during crisis times. For instance, the MSTLG reaches its minimum values during financial turmoil, evidencing the most significant level of synchronization among the global equity stock markets' returns. On the other hand, during periods of mild volatility, the MSTLG reaches its maximum values, indicating a low level of comovement among global equity returns.

Similarly, we find different levels of synchronization sensitivity among regional markets. The co-movement sensitivity of each regional equity market due to variations on the global synchronization measure is unequal. This evidence would suggest the presence of regional factors that also influence the synchronization of the regional equity returns. These findings hold when applying robustness tests. The results remain unchanged when we apply specific controls and use the Planar Maximally Filtered Graph Length (PMFGL) as another global synchronization measure of returns instead of the MSTL.

Finally, we study the synchronization impact of global or world synchronization on the behavior of world regional markets. Using structural VAR and impulse-response function analysis, we find evidence that suggests the presence of Granger causality. Moreover, this predictability seems to go from the global network of returns towards the regional returns networks. These results suggest that the global synchronization of the equity market generates a contemporary and future regional equity synchronization of returns. In other words, the global synchronization of equity returns acts as a relevant factor explaining the variation of the co-movement of returns at regional market levels.

Our evidence has practical implications for practitioners and regulators. This work shows that an increase in the global synchronization of stock returns is the forerunner of a future rise in the synchronization of returns of regional markets. In addition, this result would imply a greater systemic risk and lessen portfolio diversification benefits [17]. Similarly, our measure of global synchronization would serve to set critical value limits that would allow market participants to anticipate future regional and global markets' synchronization spurs. Finally, our results highlight the relevance of global and local factors that would fuel synchronization events [9] and the importance of proper regulation of financial markets that alleviate the potential hazards of high synchronization periods.

The paper is structured as follows: Section 2 depicts the literature and connects it with the main hypotheses. Section 3 reviews the methodology. Section 4 discusses the main methods applied and shows the data. Section 5 presents the empirical findings. Finally, Section 6 concludes and extends our findings.

\section{Literature and Hypotheses}

2.1. Literature Review. Systemic risk jeopardizes the capital markets' stability and proper functioning, reducing market confidence and willingness to take risks. Diverse methodologies have been applied to monitoring and quantifying it. Among the most applied methods are equitycorrelation-based measures [18], conditional value at risk (CoVaR) approach [19], copula functions [20], marginal expected shortfall analysis [21, 22], and cross-correlation coefficient-based analysis [23]. These approaches mainly focus on the relationships between financial institutions and the financial system.

As the interconnections on capital markets rise, the necessity of considering the interconnectedness and interactions that underlies the financial system as a whole perspective arises too. The complexity of interconnections and the size of the financial markets promote the ample use of network methodologies to quantify risks and identify the transmission of risks among sectors, countries, and markets. Moreover, understanding complex systems' behaviors are enhanced through network methods since they allow modeling the indirect effects in the interconnections of their components or entities [24].

The network literature initially focused on network attributes' implications and their relationships with financial systems' stability and fragility [25, 26]. Similarly, many studies explored how the links' distribution affects the systemic reaction to shocks and how the connectivity of critical nodes or hub nodes could destabilize and even cause the entire network to collapse [3,27,28]. Other relevant topics included transaction networks of financial assets, portfolio selection, risk management, overlapped portfolios, integration of financial markets, and financial crises [29-32].

Network methods initially employed correlation-based networks. The minimal spanning tree (MST) [30], the Planar Maximally Filtered Graph (PMFG) [33], the correlation threshold network [34], and the partial correlation-based network [35] are the most extensive methods. MST and PMFG apply Pearson correlation coefficients to build asset networks considering the level of similarity in the price changes for a given pair of assets. In contrast, partial correlation-based networks estimate partial correlations to measure whether other assets influence the relationship between this pair of assets. Pearson correlation-based networks methods are applied to study financial markets, the MST being the most frequent method used for its simplicity, robustness, and clarity to visualize asset trees properties and their linkages [35].

The structure of the asset network of financial markets reveals useful taxonomies for analyzing financial markets as a complex system. Mantegna [29] models US equity market structures using MST and PMFG, finding clusters between the Dow Jones index components. Onnela et al. [31], analyzing the correlation networks of the stocks belonging to the S\&P500 index, show dynamic clusters whose existence is not exclusive due to industrial sectors but due to psychological and economic factors captured through the asset network. They find that the normalized tree length of the MST (MSTL) is dynamic over time and reaches minimums during financial crises, showing that the power of diversification in the market relates to the evolution of the MSTL asset network over time. Li et al. [36] found that during crises, the topology of the asset tree changes, the MST becoming more 
starlike and compact and this network becoming less resilient to shocks and more prone to systemic risk. Despite the widespread use of these methods as tools for studying relationships and interactions within financial markets, their main drawback is that the topological constraints for constructing these networks do not always possess apparent economic or statistical grounds $[37,38]$.

As interest in the phenomenon of financial market interconnections increases, new methodologies have developed to delve into the mechanisms of spillover and contagion. Spillover analysis method surge founded on econometric-based networks is classified into the following groups: (a) Granger-causality networks or mean-spillover networks [1]; (b) variance decomposition frame-based networks or volatility spillover networks [39] and GARCH model-based networks [40]; and (c) risk spillover networks that include the tail-risk driven networks [41-43] and the extreme risk networks [38]. In general terms, these methods can model the complexities of the interconnectedness phenomena present in capital markets and identify their possible spillover paths associated.

Network methods improve traditional statistical analysis of complex systems. For example, econometric methods study the direct effects on the relationships of the entities of a system. However, when coupled with networks, it is feasible to enrich the dynamic modeling of financial markets by estimating, for instance, the distance between two entities or nodes and how likely an indirect effect is between them [39]. Mainly, through network methods, it is possible to study the synchronization of returns in financial markets.

The ubiquity of the synchronization of returns is a phenomenon with multiple origins and implications. Glasserman and Young [5] found that, at present, the returns synchronization observed in the financial markets is more recurrent than before because of the growing interconnectedness of the world financial system. This issue is critical in a risk management context, because diversification does not properly protect portfolios against risk during high synchronization episodes. Ample evidence shows that, during the Subprime Crisis, the diversification advantage from portfolio management disappears due to increased synchronization of assets' returns [17, 44, 45]. Bury [46], Zhao et al. [47], and Gao and Mei [48] found that correlations are time-varying and synchronization of returns rises during crises. Higher synchronization periods tend to occur precisely when investors mostly need the help of diversification as a tool to lessen the adverse effects of financial shocks on their portfolios [31].

As the focus of our paper is the study of synchronization within global equity markets, we use the MST method. As mentioned, this is an excellent technique for studying the structure of financial time-series correlation networks and very useful for identifying the structure of financial timeseries correlation networks [31, 49, 50]. Moreover, even though there are more sophisticated techniques to measure synchronization based on oscillators [51, 52] or phase synchronization $[53,54]$, the returns cross-correlation matrix is, in essence, the information of co-movement between signals, easy to compute and from which one can extract not only topological properties of the correlation network but also coupling behavior of time-varying signals.

From an economic and financial viewpoint, various theories would explain the synchronization of returns. Factors related to financial exposures and economic and commercial links, coupled with dynamic complex network structures, have been studied [46, 51, 55]. For instance, interest rate parity models link the synchronization of returns to exchange rates; trade flow models connect them to exchange rates, and asset pricing models associate them with exchange rate variations that affect the supply/demand of financial assets. Roll [56] and Chow et al. [57] found a positive relationship between the US dollar and stock returns. Phylaktis and Ravazzolo [58] observe that stock prices and exchange rates are positively related. In the same vein, but connecting different financial markets, Ciner et al. [59] showed that oil shocks negatively impact stock returns, and during crises, gold transforms into a refuge asset. Recently, Raddant and Kennet [9] related the co-movement of financial markets to countries' economic structural similarities and alike global sectoral factors.

2.2. Hypotheses. Network methods complement traditional econometric analysis since they allow the inclusion of second-order effects and nonlinear interactions present on complex systems. For instance, modeling the synchronization of returns is crucial for understanding the financial markets' behavior and reaction to disturbances always present on capital markets.

In opposition to linear systems, complex systems are characterized among other factors, by being nonlinear because the change in the outputs is nonproportional to the change in the inputs, causing the system to appear chaotic, unpredictable, or even contradictory. Precisely, we have witnessed this kind of behavior during the outbreak of the pandemic in equity markets, in part due to the extraordinary measures taken by central banks and governments and in part also as a natural reaction of investors towards a flight to quality investing as a consequence of a diminished risk appetite. To mitigate markets turmoil, liquidity injections, repurchase of risky assets, and the explosive increase in fiscal spending have been applied globally. Unfortunately, these measures have been accompanied by unwanted higher synchronization in the global equity market.

Capital markets are characterized by numerous entities and various interaction rules, on several degrees with nonlinearities, that generate collective behaviors and comovements that stimulate asset and market interactions that finally influence pairwise returns correlations under a specific catalyst. This generalized phenomenon hinders the comprehension and modeling of the whole system, especially when shocks generate state changes in global financial markets that skyrocket returns' synchronization [46, 51].

From the viewpoint of the market participants and regulators, today more than ever, it is needed to measure, monitor, and anticipate global synchronization of the returns of financial assets, especially for most volatile ones such as stocks. Therefore, central banks, regulators, portfolio 
managers, and investors require estimation of synchronization of the global, regional, and local level in order to use this measure as a "seismograph" that can help them to assess the movements that different shocks provoke on the financial system and at the same time be able to foresee the future level of synchronization.

We consider the contribution of financial networks as a tool to monitor the level of synchronization of returns of global stock markets. Based on the purpose mentioned above, considering the research questions mentioned in Introduction and considering the level of global synchronization of equity markets as an exogenous variable that evolves accordingly to the positive and negative shocks that financial markets face, we establish the following hypotheses:

Hypothesis 1 (H1): the global synchronization of returns (MSTLG) is a statistically significant factor in explaining the synchronization of returns of regional markets (MSTLR) of North and Latin America, Europe, Asia, and Oceania.

We expect that the global synchronization of returns estimated from the global equity market network is relevant to explaining the regional synchronization of returns. This global network captures the collective behavior at the aggregate level of pairwise markets correlations. Our second hypothesis is the following:

Hypothesis $2(\mathrm{H} 2)$ : there are statistically significant differences in the degree of sensitivity of each regional markets' synchronization (MSTLR) to changes in the global synchronization of returns (MSTLG).

We expect that changes in the global synchronization levels affect market's synchronization of each regional market unequally since multiple local and global factors coupled with economic and commercial links affect the co-movements of stocks.

\section{Network Methods}

We apply network methodologies to stock indexes to estimate the correlations of market returns and build the network of correlations $[31,60]$. For this, we considered the closing price of the index $i$ on the day $\tau$ as $P_{i}(\tau)$ and its returns as $r_{i}(\tau)=\ln P_{i}(\tau)-\ln P_{i}(\tau-1)$ for a consecutive sequence of transaction days. To calculate the evolution of indices' synchronization, we used a vector of returns for a time window defined by the number of transaction days of month $t$. This vector of returns corresponds to $\mathrm{r}_{i}^{t}$, such that the correlation between index $i$ and index $j$ in month $t$ is

$$
\rho_{i j}^{t}=\frac{\left\langle\mathbf{r}_{i}^{t} \mathbf{r}_{j}^{t}\right\rangle-\left\langle\mathbf{r}_{i}^{t}\right\rangle\left\langle\mathbf{r}_{j}^{t}\right\rangle}{\left[\left\langle\mathbf{r}_{i}^{2}\right\rangle-\left\langle\mathbf{r}_{i}^{t}\right\rangle^{2}\right]\left[\left\langle\mathbf{r}_{j}^{t 2}\right\rangle-\left\langle\mathbf{r}_{j}^{t}\right\rangle^{2}\right]},
$$

where $\langle\ldots\rangle$ indicates the average overall transaction days of month $t$. The result for each pair of indexes is a matrix $\mathbf{C}^{t}$ of $N \times N$ with values $-1 \leq \rho_{i j} \leq 1$. This matrix is equivalent to the adjacency matrix with weights of a completely connected network, in which the interconnection of each index is represented and in which the weights correspond to the correlations between each pair of indices.
To capture the relevant correlations in the index network, we filtered the entire network's weights, preventing the network nodes from being disconnected. This methodology corresponds to the MST [29], which delivers a subgraph-type tree structure, connected from the entire network, with $\mathrm{N}$ nodes and $\mathrm{N}-1$ links, and whose path to connect all nodes is minimal. The MST reduces the entire network of $\mathrm{N}(\mathrm{N}-1) / 2$ links to a tree with $\mathrm{N}-1$ links [61].

The MST built with Prim's algorithm [62] connects the asset network's $\mathrm{N}$ nodes minimizing the distance traveled. Previous to this network, we transformed the correlations using a nonlinear transformation such that $d_{i j}=(2(1-$ $\left.\left.\rho_{i j}\right)\right)^{1 / 2}$ represents the distance between the indices. A correlation $\rho_{i j}=-1$ indicates the maximum distance with $d_{i j}=2$, while $\rho_{i j}=1$ indicates a minimum with $d_{i j}=0$. As a result, we obtained a matrix $D^{t}$, which summarizes the distances between the indices that describe the ultrametric properties of the taxonomy of an asset network [29, 63, 64].

We estimate the MST at $D^{t}$, describing the asset network's adjacency matrix by $T^{t}$, whose sum of links is minimal. The sum of the links calculated for each month $t$ forms a time series. In this way, for the network of $\mathrm{N}$ nodes and $\mathrm{N}-1$ links, the normalized tree length (MSTL) is defined as

$$
L(t)=\frac{1}{N-1} \sum_{d_{i j}^{t} \in \mathbf{T}^{t}} d_{i j}^{t}
$$

We generated a time-series $\operatorname{MSTL}_{i}(t)$ for each month $t$ and market $i$, taking its variation as

$$
\Delta L_{i}(t)=\ln \left(L_{i}(t)\right)-\ln \left(L_{i}(t-1)\right) .
$$

Finally, to properly model this series, we study the stationarity conditions of this time series applying standard procedures to include them in the econometric models $[65,66]$.

\section{Empirical Approach}

4.1. Econometric Model. Our paper analyzes the hypotheses related to the global synchronization of 27 equity markets and the synchronization observed in the regional markets of North and Latin America, Europe, Asia, and Oceania. According to this, we built the following time-series model to test the hypotheses of this study:

$$
\Delta L_{i t}=\alpha+d_{m}+\beta * X_{i t}+\gamma * C_{i t}+e_{i t} .
$$

The dependent variable $\Delta L_{i t}$ is the MSTLR variation of region $i$ ( $i=1$ : America; 2: North America; $i=3$ : Latin America; $i=4$ : Europe, and $i=5$ : Asia-Oceania) in month $t$ $(t=1 \ldots 216) ; \alpha$ is the constant; $d_{m}$ is a dummy month variable that captures unobserved temporary effects $(m=1$, January, . ., $m=12$, December); $\beta$ represents the coefficients of the independent variables related to the hypotheses; $\gamma$ corresponds to the estimated coefficients for the control variables; $X_{i t}$ is the global MSTL variation (MSTLG); $C_{i t}$ are the control variables; and $e_{i t}$ corresponds to the error term. In addition, we include lags $\Delta L_{i t-1}$ and $\Delta L_{i t-2}$ to control the 
possible effects of autocorrelation. Finally, we include as an independent variable, the monthly variation (varmstl_global) of the length of the global minimum spanning tree (MSTLG) as the variable that captures the global synchronization of stock returns.

In this way, using the model of equation (4), we evaluate the following hypotheses previously depicted in Section 2:

Hypothesis 1 (H1): the global synchronization of returns (MSTLG) is a statistically significant factor in explaining the synchronization of returns of regional markets (MSTLR) of North and Latin America, Europe, Asia, and Oceania.

$H_{0 i}: \beta_{i}=0$ and $H_{1 i}: \beta_{i} \neq 0$, for all $i=1,2,3,4$, and 5 . Hypothesis 2 (H2): There are statistically significant differences in the degree of sensitivity of each regional market's synchronization (MSTLR) to changes in the global synchronization of returns (MSTLG).

$H_{0}: \quad \beta_{1}=\beta_{2}=\beta_{3}=\beta_{4}=\beta_{5}$ and $H_{1}: \beta_{1} \neq \beta_{2} \neq \beta_{3} \neq$ $\beta_{4} \neq \beta_{5}$.

We applied heteroscedasticity and autocorrelation consistent (HAC) estimators to estimate our econometric models. In addition, we implement robustness tests to verify that the results of the econometric analysis are consistent when including different robustness checks (see Section 5.3). Finally, we apply structural VAR, impulse-response function analysis, and forecasting error variance decomposition methods to our core models to test the existence of Granger causality among global and regional synchronization of equity returns (see Section 5.3).

4.2. Control Variables. In this section, we explain the control variables included in the econometric model of Section 4.1. According to the literature, financial shocks impact economic growth and stock returns. Nguyen et al. [67] found that commodities impact stock returns due to their utilization in portfolio diversification and hedging strategies. They also indicate that this factor would explain the comovement of copper with global stock markets. Similarly, interest rates also have an impact on stock markets. For instance, Shiller and Beltratti [68] found a negative relationship between long-term interest rates and stock returns in US markets. Likewise, there is evidence of a link between stock returns and exchange rates. Roll [56] and Chow et al. [57] showed a positive correlation between the dollar value measured by a basket of foreign currencies and US stocks‘ returns.

Commodities also impact the behavior of stock returns, especially the high correlation between oil prices and stock returns. Park and Ratti [69] and Apergis and Miller [70] documented an intertemporal relationship between oil and stocks, the positive or negative impact being on stock markets dependent on the type of oil shock. Along the same lines, there is evidence of a relationship between gold prices and stocks' behavior. Ciner et al. [59] pointed out that gold has a shelter status because investors use it as a haven under shocks and high uncertainty levels.
Uncertainty also influences the behavior of equity returns. The literature evidences a relationship between stock returns, market volatility, and economic uncertainty. The CBOE VIX (Chicago Board Options Exchange Volatility Index) is the best gauge to forecast volatility of equities, and it is an indicator highly valued by investors as a measure of implied equity market uncertainty. Banerjee et al. [71] found a negative relationship between the S\&P 500 performance and VIX evolution. They also observe that the VIX has a robust predictive capacity of future stock returns. Similarly, Antonakakis et al. [4] found a negative correlation between stock's performance and the VIX. They also indicate that increases in the volatility of returns reduce future returns and boost economic uncertainty.

Considering the above literature, we incorporate control variables in our econometric model of Section 4.1 to control the possible impact that the previous variables would have on the market's returns of the equity markets of our study, which could influence the behavior of our dependent variable. Accordingly, following Eberhard et al. [32] and Lavin et al. [13], the variables we consider as controls are the following: to consider the possible effect of volatility, we added the monthly volatility of each region (sigma); to incorporate the effect of the VIX, we added the monthly variation of the VIX index (varvix); to control the effect of the US dollar, we added the monthly variation of the US dollar (measured against a basket of 10 leading global currencies) (varbdxy); to consider the possible effect of the interest rates, we added the monthly variation of the 10-year Treasury bond rate (vart10us); to incorporate the possible influence of the gold, we included the monthly variation of the gold price (varau); and finally, to control the effect of raw materials, we added the monthly variation of the copper price (varhg1) and the monthly variation of the oil price (varcl1).

4.3. The Data. We used daily data collected from Bloomberg from July 2001 to April 2020, totaling 226 months, for 27 stock indexes from North America, Latin America, Europe, Asia, and Oceania. These indices are part of Bloomberg's top benchmarks for each stock market at the country and regional level. Table 1 exhibits the stock indices for each region. Table 2 shows monthly variations and describes the main descriptive statistics for the global MSTL (MSTLG) and regional MSTL (MSTLR).

When comparing the different estimates, North American and European markets have a coefficient of variation $(\mathrm{CV})$ higher than the global average. In contrast, Latin America, Asia, and Oceania have a lower one. These results indicate that in terms of the variability of MST length, the North American and European markets show higher volatility (relative to the average) in their degree of synchronization of returns than the rest of the regional markets. Figure 1 also exhibits the time series of the MSTLG from July 2001 to April 2020. As can be seen, there are big swings during the period, with clear maximums and minimums that tend to repeat during the whole period. 
TABLE 1: Indices by region.

\begin{tabular}{|c|c|}
\hline Region & Indices \\
\hline $\begin{array}{l}\text { Nort } \\
\text { Ame }\end{array}$ & S\&P500, NASDAQ from the USA and TSX from Canada. \\
\hline Latin America & $\begin{array}{l}\text { IPC from Mexico, BOVESPA from Brazil, IPSA from Chile, MERVAL from Argentina, IGBVL from Peru, and COLCAP } \\
\text { from Colombia. }\end{array}$ \\
\hline Europe & $\begin{array}{c}\text { FTSE from the UK, CAC from France, DAX from Germany, IBEX from Spain, MIB from Italy, AEX from Holland, OMX } \\
\text { from Sweden, RTS from Russia, and SMI from Swiss. }\end{array}$ \\
\hline Asia & $\begin{array}{c}\text { NIKKEI from Japan, HANG-SENG from Hong Kong, KOSPI from Korea, TSE from Taiwan, JSE from Indonesia, KLCI } \\
\text { from Malaysia, and ST from Singapore. }\end{array}$ \\
\hline Oceania & ASX 200 from Australia and NZSE from New Zealand. \\
\hline
\end{tabular}

This table summarizes each region of study and its corresponding stock indices.

TAble 2: Descriptive statistics of minimum spanning trees length by region (MSTLR) and global (MSTLG) measure.

\begin{tabular}{|c|c|c|c|c|c|c|c|c|c|c|c|c|}
\hline & \multicolumn{2}{|c|}{ Global } & \multicolumn{2}{|c|}{ North America } & \multicolumn{2}{|c|}{ Latin America } & \multicolumn{2}{|c|}{ America } & \multicolumn{2}{|c|}{ Europe } & \multicolumn{2}{|c|}{ Asia-Oceania } \\
\hline & MSTL & $\begin{array}{c}\text { Monthly } \\
\text { variation \% }\end{array}$ & MSTL & $\begin{array}{c}\text { Monthly } \\
\text { variation \% }\end{array}$ & MSTL & $\begin{array}{c}\text { Monthly } \\
\text { variation \% }\end{array}$ & MSTL & $\begin{array}{c}\text { Monthly } \\
\text { variation \% }\end{array}$ & MSTL & $\begin{array}{c}\text { Monthly } \\
\text { variation \% }\end{array}$ & MSTL & $\begin{array}{c}\text { Monthly } \\
\text { variation \% }\end{array}$ \\
\hline Mean & 13.045 & -0.151 & 0.786 & -0.184 & 3.379 & -0.059 & 4.539 & -0.092 & 2.932 & -0.229 & 4.813 & -0.174 \\
\hline SD & 1.949 & 14.93 & 0.191 & 30.127 & 0.574 & 18.681 & 0.778 & 18.809 & 0.683 & 25.228 & 0.772 & 16.53 \\
\hline $\mathrm{CV}$ & 0.149 & - & 0.243 & - & 0.170 & - & 0.174 & - & 0.233 & - & 0.160 & - \\
\hline p $25 \%$ & 11.516 & -8.72 & 0.641 & -22.571 & 3.042 & -11.167 & 4.046 & -10.195 & 2.423 & -16.151 & 4.219 & -9.783 \\
\hline p $50 \%$ & 13.302 & -0.325 & 0.766 & 1.735 & 3.999 & -0.342 & 4.639 & 1.064 & 2.908 & -1.444 & 4.805 & 0.160 \\
\hline p75\% & 14.598 & 10.137 & 0.914 & 19.520 & 3.785 & 11.124 & 5.158 & 10.477 & 3.441 & 16.518 & 5.434 & 9.869 \\
\hline
\end{tabular}

This table summarizes the means of the minimum spanning trees lengths by region and global levels, their respective monthly variations, and their main statistics for the period July 2001-April 2020. SD: standard deviation; CV: coefficient of variation; p $25 \%$, p50\%, and p $75 \%$ : percentile $25 \%, 50 \%$, and $75 \%$, respectively.
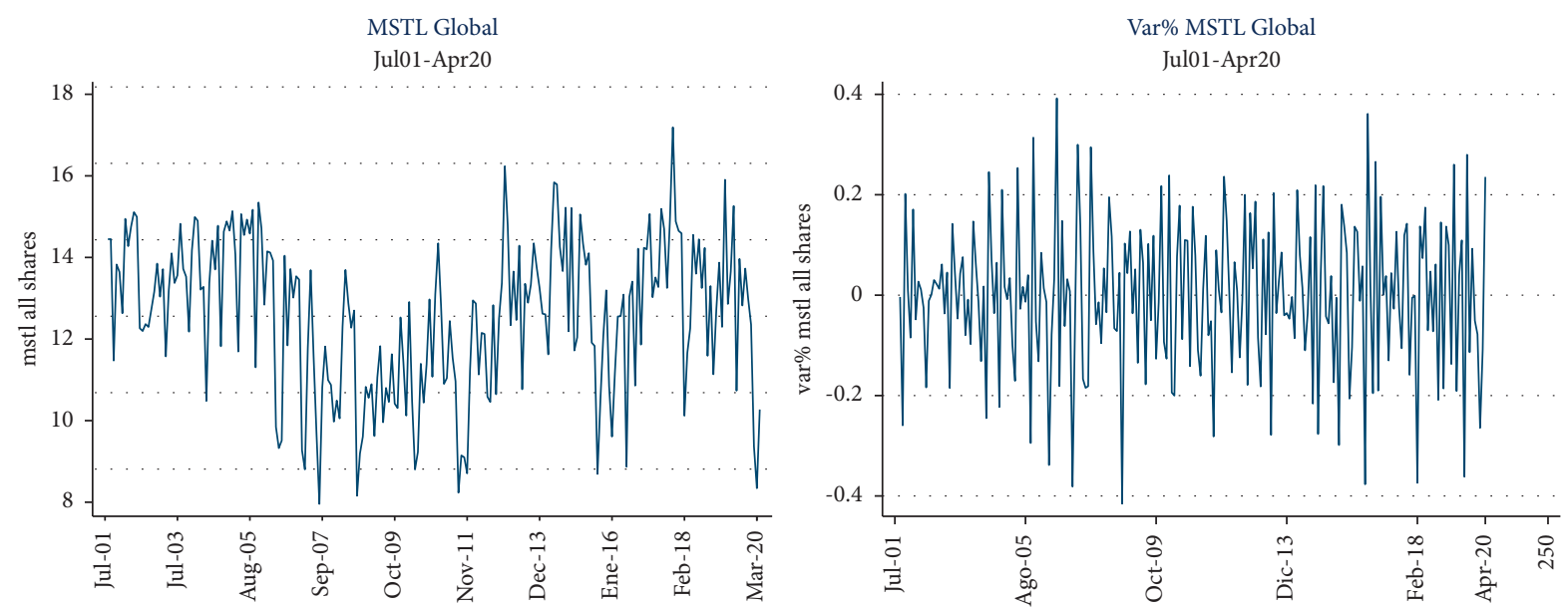

FIGURE 1: Global minimum spanning tree length (MSTLG). This figure represents the evolution and variation of the minimum spanning tree length for a total of 27 stock indexes in North and Latin America, Europe, Asia, and Oceania for the period July 2001-April 2020.

\section{Empirical Findings}

5.1. Descriptive Results. Considering our measure of global synchronization, in this section, we perform a brief comparison of the evolution of the MSTLG during the fullsample period and two periods of high turmoil in the financial markets, namely, the Subprime Crisis and the initial stages of the COVID-19 outbreak. The idea is to observe how our global synchronization measure behaves.

Figure 1 shows the monthly evolution and the monthly variation of the minimum spanning tree length for a total of
27 stock indexes in North and Latin America, Europe, Asia, and Oceania for the period July 2001-April 2020. As mentioned, this measure captures the global length of the MST asset conformed by the whole equity markets of our sample. In terms of the behavior of the MSTLG, we observe that the time series is dynamic over time, with clear cycles and pathways, reaching maximum levels near February 2018 and minimum levels near September 2017 and March 2020. In terms of the monthly variation of the MSTLG, we appreciate mild periods of change combined with high periods of fluctuations that broadly range from $+40 \%$ to $-40 \%$ monthly. 


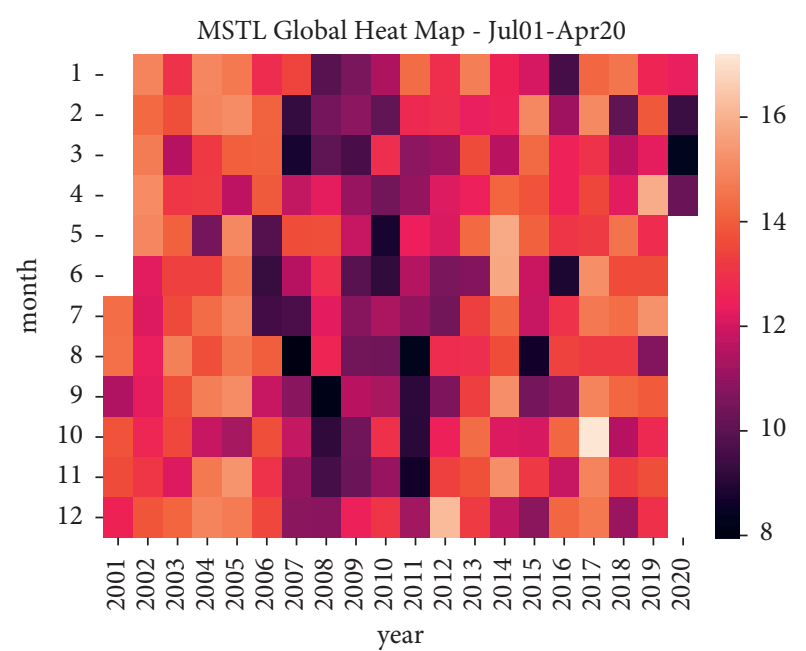

FIgURE 2: Global minimum spanning tree length (MSTLG) heat map. This figure represents the evolution of the minimum spanning tree length for a total of 27 stock indexes in North and Latin America, Europe, Asia, and Oceania for the period July 2001-April 2020. Black (khaki) color represents the minimum (maximum) values for the period.

Complementing the above evidence, Figure 2 depicts a heat map with the dynamic evolution of the MSTLG for the period July 2001-April 2020. Black (khaki) color represents the minimum (maximum) values for the period. We can observe the following:

(1) The global synchronization of the equity markets changes over time.

(2) The heat map illustrates that the minimum levels of the MSTLG coincide with shocks associated with the Subprime Crisis and the initial stages of the COVID19 outbreak. This evidence suggests that two different shocks have a similar impact on the global synchronization of the equity returns of a broad sample of stock markets.

(3) The MSTLG shrinks to its minimum levels, indicating the returns of the global stock markets are moving in a synchronized way. Unfortunately, such aggregate behavior coincides with the worst periods in terms of performance and volatility of global stock markets.

In addition to the previous analysis, we perform network analysis to understand the structural changes within the asset trees that underlie the MSTLG during periods of high synchronization. Figure 3(a) shows nodes grouped according to their geographical region during the Subprime Crisis of 2008-9. In addition, we observe a persistent behavior on nodes in the same geographical sector remaining close to each other during and after the crisis (precrisis: January, February, and March 2008; crisis: September, October, and November 2008; and postcrisis: March, April, and May 2009). The shortening and lengthening of the MSTL do not break up the geographic node clusters, but it is present according to the analysis period.

We note that the Subprime Crisis caused important changes in the stock market synchronization. The length of the tree shortens from 10.87 to 10.24 , while during the recovery from the crisis, the length increases from 10.24 to 11.68. Similarly, we observe that the structure of the trees is dynamic. Before the crisis, the tree has very long branches from several nodes joined sequentially, leaving only $L=9$ terminal nodes with leaves, while in the postcrisis period, the tree has more star formations. As a result, more nodes appear as terminal nodes and more hub nodes; in this case, $L=16$. We believe that this is relevant to the way information is transmitted throughout the financial network. The flow of information in a network with more star formations and hub nodes is different from a network with sequentially connected nodes. The average diameter of the tree $D$ (the largest distance between any two nodes) also changes in the periods indicated. As expected, the diameter decreases (from 5.72 to 5.10), but it continues to do so even in the postcrisis period. Nevertheless, this decrease is due to the change in the tree's structure in which we see that the long rows of connected nodes give way in favor of more significant number of terminal nodes.

In the same way, we analyze how the network topology reacts during the initial months of the pandemic. Figure 3(b) shows the MST before (November 2019 to January 2020) and during the COVID-19 outbreak (February to April 2020). Like the Subprime Crisis, this shock does not seem to "disorder" the nodes, maintaining the network at a certain grouping level according to the region to which they belong. In any case, we observe a significant contraction of the distances (from 14.40 to 9.30). Unlike the Subprime Crisis, the trees' shape does not seem to change much: the number of terminal nodes before and during the COVID-19 outbreak is $L=12$ and $L=13$, respectively. However, the diameter also decreases significantly from 6.64 to 3.81 . This reduction is due to the effect of this shock on financial markets and not a radical change in the network's topology.

In addition, we compare the effect of both shocks on the structure of the asset network. For this goal, we analyze the value of $\mathbf{L}_{\mathbf{f}}$ and $\mathbf{D}_{\mathbf{n}}$ between both asset trees. The first measure is the number of leaves divided by the maximum number of potential leaves (a starlike tree). The second measure is the diameter divided by the total number of edges. Table 3 summarizes these estimates. We can appreciate that the increase in $\mathbf{L}_{\mathbf{f}}$ before and during both episodes was $8.7 \%$ and $30 \%$ for the Subprime Crisis and the COVID19 outbreak, respectively. However, the decrease in $\mathbf{D}_{\mathbf{n}}$ was $9.1 \%$ and $42.3 \%$, respectively. In other words, on the one hand, the COVID-19 shock produced a significant topological change based on a relative increase in the number of leaves, while the Subprime Crisis produced an important topological change based on the diameter. Although the mechanisms that explain how and why both shocks affect the structure of the correlation networks differently are not precise, we know that both events' origin and basis are entirely different and both have different implications on the global financial and stock markets. Notwithstanding the previous results, from the viewpoint of the synchronization phenomenon, the previous results indicate that both episodes resemble each other, as the global synchronization increase in both periods. 

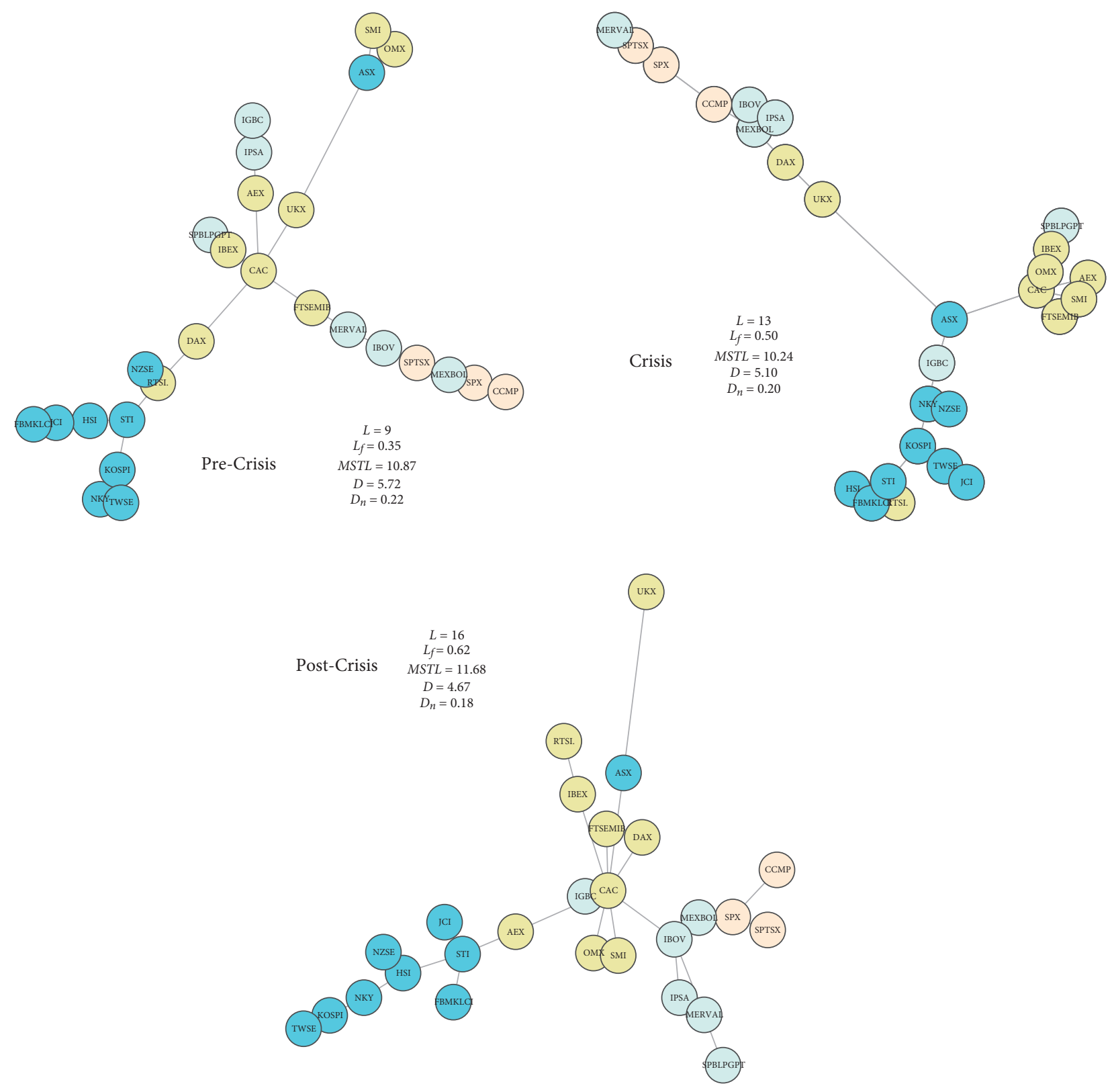

(a)

Figure 3: Continued. 


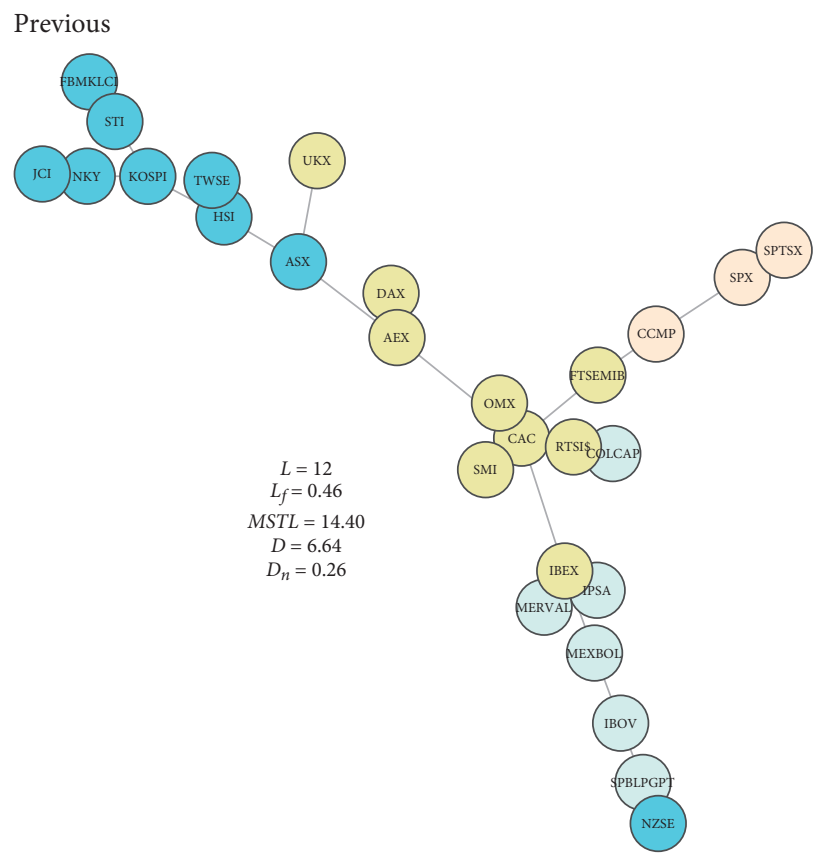

During

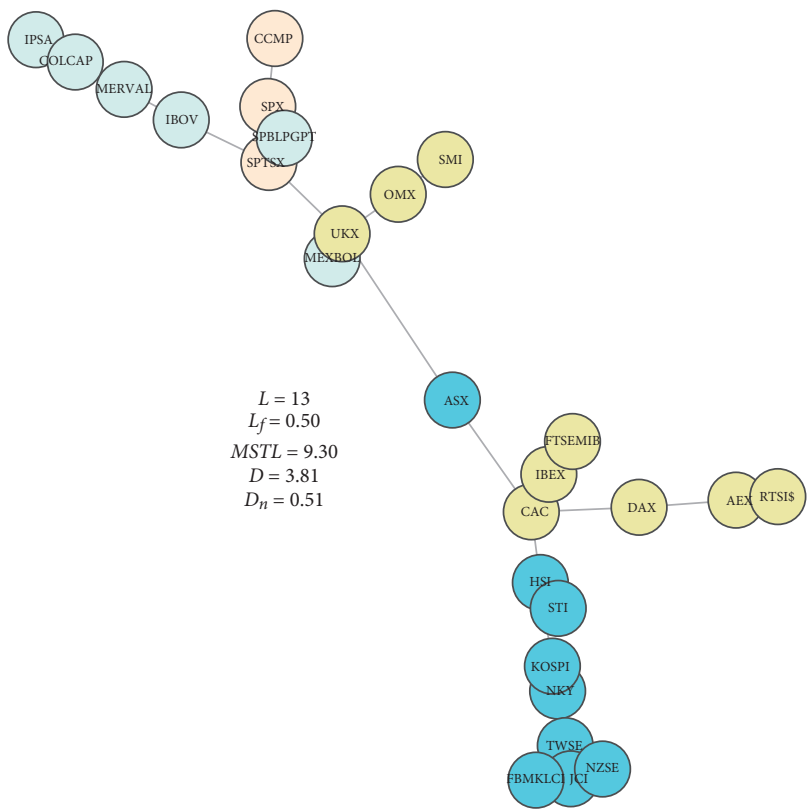

(b)

FIgURE 3: (a) Minimum spanning trees (MSTs) during the Subprime Crisis. This figure shows the resulting MST for three different periods. For comparison, we consider the quarters 6 months before and after where global markets fell sharply during Subprime Crisis: precrisis (January, February, and March 2008), crisis (September, October, and November 2008), and postcrisis (March, April, and May 2009). The color of the vertex represents different regions: (a) blue: Asia-Oceania, (b) light blue: Latin America, (c) light yellow: Europe, and (d) light salmon: North America. (b) Minimum spanning trees (MSTs) during the COVID-19 outbreak. This figure shows the resulting MST for two different periods. For comparison, we consider the quarter where global markets fell sharply during the COVID-19 outbreak and a quarter before: previous (November 2019 to January 2020) and during (February to April 2020) the outbreak. The color of the vertex represents different regions: (a) blue: Asia-Oceania, (b) light blue: Latin America, (c) light yellow: Europe, and (d) light salmon: North America.

5.2. Econometric Results. In this section, we resume the main results of the econometrics model presented in Section 4 that study our main hypotheses. As mentioned, H1 evaluates whether the global synchronization of returns (MSTLG) is a statistically significant factor in explaining the synchronization of returns of regional markets (MSTLR), while $\mathrm{H} 2$ 
TABLE 3: Descriptive parameters of the structure of the minimum spanning trees.

\begin{tabular}{lcccc}
\hline & \multicolumn{2}{c}{ Subprime Crisis } & \multicolumn{2}{c}{ COVID-19 outbreak } \\
Period & $L_{\mathrm{f}}$ & $D_{\mathrm{n}}$ & $L_{\mathrm{f}}$ & $D_{\mathrm{n}}$ \\
\hline Before & 0.35 & 0.22 & 0.46 & 0.26 \\
During & 0.50 & 0.20 & 0.50 & 0.15 \\
After & 0.62 & 0.18 & - & - \\
\hline
\end{tabular}

This table compares the means for $L_{\mathrm{f}}$ and $D_{\mathrm{n}}$ parameters of the MST trees during the Subprime Crisis and the COVID-19 outbreak. $L_{\mathrm{f}}$ : the number of leaves divided by the maximum number of potential leaves of the tree; $D_{\mathrm{n}}$ : the diameter divided by the total number of edges of the tree; periods of Subprime Crisis: precrisis: January to March 2008; crisis: September to November 2008; and postcrisis: March to May 2009. COVID-19 outbreak: before: November 2019 to January 2020; during: February to April 2020.

tests whether there are statistically significant differences in the sensitivity of each regional market (MSTLR) to variations in the global synchronization of equity returns (MSTLG).

Table 4 resumes the main results of the econometric estimations. First, we observe that MSTLG is a relevant factor for explaining the synchronization behavior of the regional markets under study (columns 1, 3, 5, 7, and 9). Second, as indicated by the coefficients associated with the variation of MSTLG (varmstl_global), there is a positive relationship between the variations in the global synchronization of equity returns and the variations in the level of regional synchronization associated with each regional market. Specifically, we can observe that the elasticities for North America, Latin America, America, Europe, and AsiaOceania are $0.967,0.858,0.951,1.083$, and 0.772 , respectively, all of them with $p<0.001$. These coefficients suggest different levels of exposure to the risk of synchronization of global markets: the degree of linkage that a region has with the synchronization of returns on a global scale. Europe has a greater sensitiveness. A change of $1 \%$ in the global MSTL (MSTLG) causes a reaction of $1.08 \%$ in the synchronization of returns in European markets. Contrarily, for the AsiaOceania markets, the impact is just $0.73 \%$. The latter result suggests the lowest synchronization sensitivity among rest of the regional markets.

The above comparisons of regional sensitiveness regarding global synchronization are valid as long as the coefficients for each market are statistically different. Table 5 , panel A, displays a statistical test of coefficient equality between models. As can we see, the evidence indicates Europe and Asia-Oceania have different elasticities suggesting that both regions would have different global synchronization exposures. On the contrary, North America and Europe exhibit similar elasticities suggesting that both regions respond similarly to changes in the global level of synchronization.

In addition, it is worth mentioning that the results of Table 4 are in line with the previous literature that indicates that the impact of regional stock volatility on returns co-movement is a relevant factor. As can we observe, there is a negative relationship between regional volatility and the synchronization of stock returns. The latter would occur because when regional volatility rises, a reduction in the regional MSTL develops as a consequence of a shock, indicating a higher level of correlation among regional stock markets, i.e., a higher regional synchronization episode emerges. These results are very interesting since a local volatility shock coupled with a global shock of synchronization would further increase the regional synchronization (columns 1 and 9).

5.3. Robustness Analysis. This section presents additional analyses to provide further insights and test the latter results' robustness. Accordingly, we apply three kinds of robustness analysis: (1) we control the possible impact of financial turmoil episodes; (2) we replace our global synchronization measure based on the length of the MST by the length of the PMFG; and (3) we study the influence of global synchronization on regional synchronization using VAR analysis.

5.3.1. Controlling Financial Shocks. During financial turmoil, the risk appetite practically disappears, giving space to liquidity hoarding and flight to quality. The above negatively impact risky assets, their returns, and their valuations. Accordingly, to evaluate the consistency of the results presented in the previous section, we apply robustness tests for controlling possible effects related to past financial shocks, such as the financial crisis of 2001, the Subprime Crisis of 2008-9, the financial turmoil of 2018, and the COVID-19 outbreak. During these episodes, the MSCI All Country World Index, a global free-float equity weighted index that includes both emerging and developed world markets, experienced negative accumulated returns from peak to valley, of $-51 \%,-60 \%,-21 \%$, and $-34 \%$. According to market practitioner's view, they entered a bearish territory because they fell more than $20 \%$. For this reason, we include in the previous econometric models a dummy variable (dum_shock (The dummy shock takes the value of 1 for each month in the period from Mar-00 to Oct-02, Oct-07 to Apr-09, Jan-18 to Dec-18, and Feb-20 to Apr-20 and zero otherwise.)) to capture financial shock episodes. The idea is to corroborate that our results are not due to the financial turmoil during those specific bearish periods.

As Table 5, panel B, shows, the differences in the regional stock markets' sensitivity to changes in the global synchronization of the stock returns remain. In other words, during the analysis span, our results are consistent when controlling the unobserved effects of those above economic and financial shocks.

\subsubsection{PMFG Length as a Measure of Global Synchronization.} Our second robustness analysis tests whether our previous results hold when using a different measure to capture synchronization. We re-tested the econometric models, including 


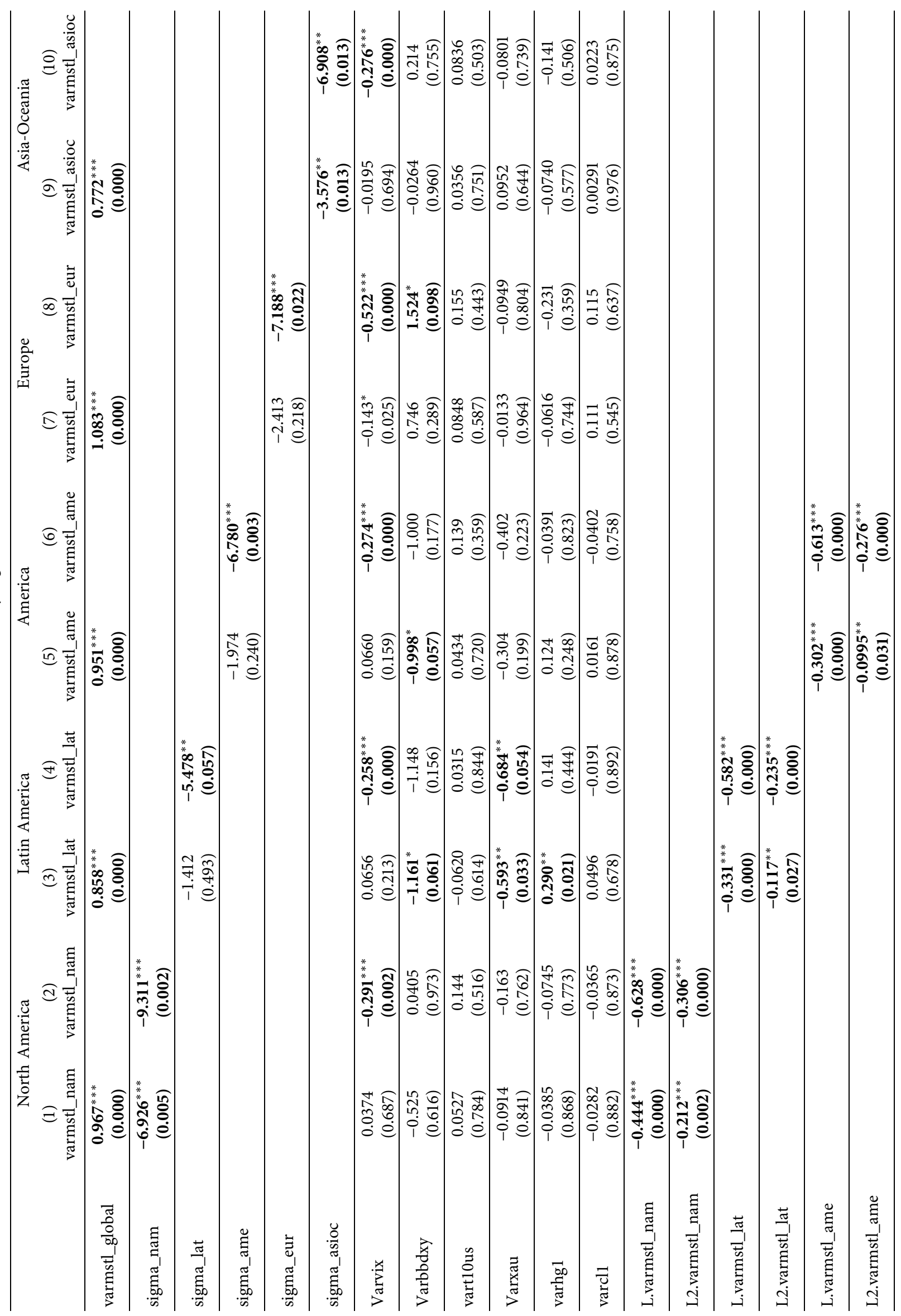




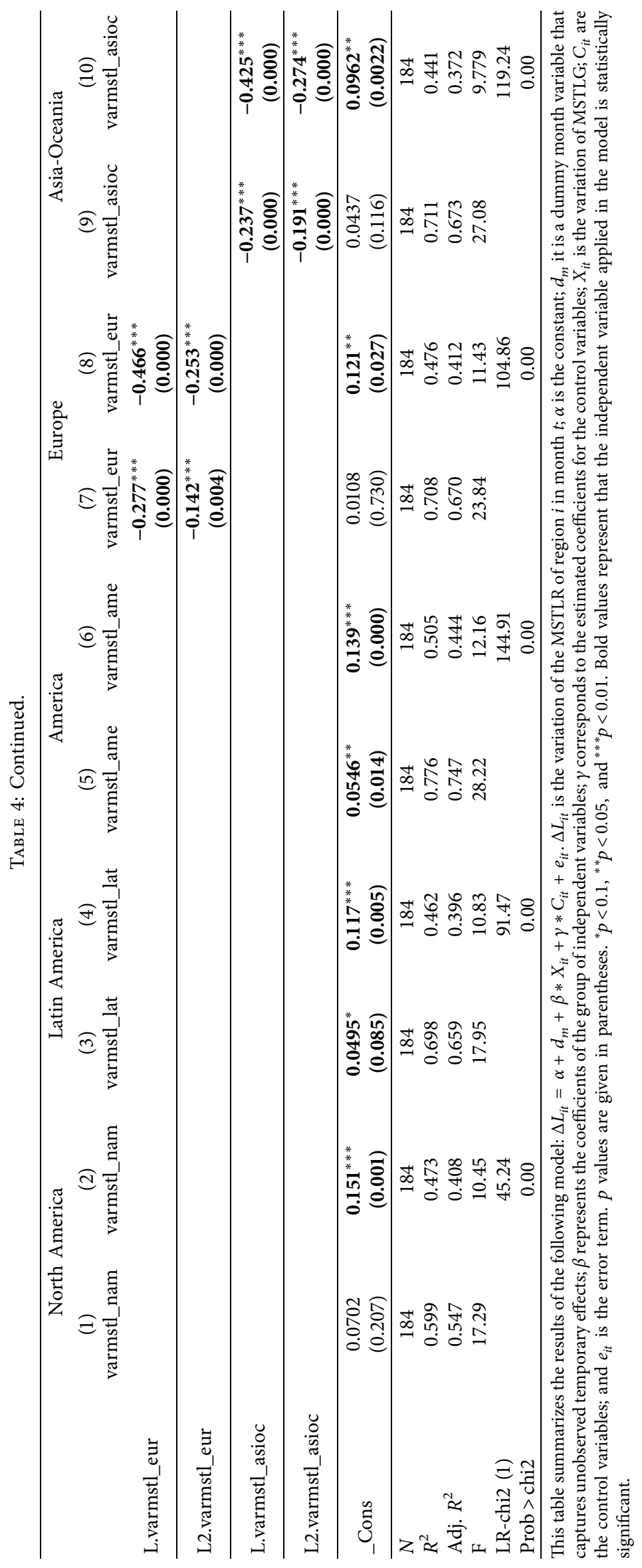


TABLE 5: Comparison between coefficients of regressions by region.

\begin{tabular}{|c|c|c|c|c|c|}
\hline & \multicolumn{5}{|c|}{ Panel A-without dummy shock } \\
\hline & North America & Latin America & America & Europe & Asia-Oceania \\
\hline North America & - & $4.92(0.0272)$ & $2.42(0.1208)$ & $0.30(0.5859)$ & $9.28(0.0025)$ \\
\hline Latin America & - & - & $1.35(0.2465)$ & $12.06(0.0006)$ & $0.90(0.3426)$ \\
\hline America & - & - & - & $7.16(0.0078)$ & $5.90(0.0157)$ \\
\hline \multirow[t]{3}{*}{ Europe } & - & - & - & - & $24.69(0.0000)$ \\
\hline & \multicolumn{5}{|c|}{ Panel B-with dummy shock } \\
\hline & North America & Latin America & America & Europe & Asia-Oceania \\
\hline North America & - & $5.03(0.0255)$ & $2.50(0.1146)$ & $0.31(0.5794)$ & $8.54(0.0037)$ \\
\hline Latin America & - & - & $1.37(0.2422)$ & $12.31(0.0005)$ & $0.83(0.3630)$ \\
\hline America & - & - & - & $7.32(0.0072)$ & $5.36(0.0187)$ \\
\hline Europe & - & - & - & - & $23.63(0.0000)$ \\
\hline
\end{tabular}

This table shows the F-tests and $p$ values (in parentheses) that compare the MSTLG coefficients between regression models shown in Table 4 . The rows and columns of the table indicate the result comparison for each region. The null hypothesis indicates that there are no significant differences between the magnitudes of the estimated coefficients.

the variation of the length of the Planar Maximally Filtered Graph as an independent variable (The algorithm to find the PMFG [33] is similar to that used to find the MST, but unlike the latter, it produces a graph with $3 \mathrm{~N}-6$ edges, unlike MST that generates $\mathrm{N}-1$ [72]. In this way, the PMFG retains a little more information than the MST.) (varpmfgl). Since the PMFG supports cycles in the network, the PMFGL will be higher than the MSTL. Because of this feature of including more information, it is interesting to compare the models that explain the synchronization phenomenon as a robustness measure. It is worth mentioning that we do not calculate the PMFG length for regions. As the PMFG includes the MST and the edges used to join the nodes in the PMFG are of minimum distance, therefore, the regional PMFG length will be the same as the length of the regional MST.

As we can see in Table 6, the principal results remain when we control the possible effect of financial shocks in conjunction with the length of the PMFG as a new estimate of global synchronization. Thus, we still observe the previous finding of a direct relationship between the global synchronization of equity markets and regional synchrony of returns. Moreover, similar to previous results, Table 6 shows that the sensitivity of the regional markets to changes on the global synchronization is dissimilar. For instance, North American and European markets have superior sensitivities compared to Latin American and AsianOceania markets.

5.3.3. VAR and IRF Analysis. Our last robustness analysis applies vector autoregression analysis (VAR) and impulseresponse function (IRF) models to understand the interactions between the variables that capture synchronization at the regional markets and the effects of global synchronization on these variables. In the general form of the VAR model, the variables considered endogenous are varmstl_nam, varmstl_lat, varmstl_ame, varmstl_eur, and varmstl_asioc, while we incorporated the variable varmstl_global as an exogenous variable. In addition, we included the variable varvix to control for possible effects derived from implied volatility spillovers [73]. The VAR model is

$$
Y_{t}=\sum_{k=1}^{K} A_{k} Y_{t-k}+\sum_{l=0}^{L} B_{l} X_{t-l}+e_{t}
$$

where $Y_{t}$ is an $\mathrm{nxl}$ vector of period $t$ observations of endogenous variables; $X_{t}$ is a vector of period $t$ observations of the exogenous variables; and $\mathrm{e}_{t}$ is an $n x 1$ residual vector. $\mathrm{K}$ is the number of lagged endogenous observations, and $L$ is the number of lagged control observations. We set $K=4$ and $L=0$ based on the Akaike information criterion. The IRF function is

$$
\left[\begin{array}{c}
\text { varmstl_nam }_{t} \\
\text { varmstl_lat }_{t} \\
\text { varmstl_ame }_{t} \\
\text { varmstl_eur }_{t} \\
\text { varmstl_asioc }_{t}
\end{array}\right]=\sum_{k=1}^{K} A_{k}\left[\begin{array}{c}
\text { varmstl_nam }_{t-k} \\
\text { varmstl_lat }_{t-k} \\
\text { varmstl_ame }_{t-k} \\
\text { varmstl_eur }_{t-k} \\
\text { varmstl_asioc }_{t-k}
\end{array}\right]+B_{l} * \mathrm{BM}_{t}+\left[\begin{array}{c}
\varepsilon_{v_{\text {varmstl_nam }, t}} \\
\varepsilon_{\text {varmstl_lat }, t} \\
\varepsilon_{\text {varmstl_ame }, t} \\
\varepsilon_{\text {varmstl_eur }, t} \\
\varepsilon_{\text {varmstl_asioc, } t}
\end{array}\right] .
$$

Table 7 summarizes the results of the full-sample VAR. Again, we emphasize that we are not attempting to identify spillover effects, either the channels of transmissions by any means; on the contrary, we are just interested in studying the dynamic effects of the aggregate system (e.g., establishing if one variable helps forecast the other beyond a simple autoregressive benchmark). We organized our analysis in columns for each dependent variable and by 


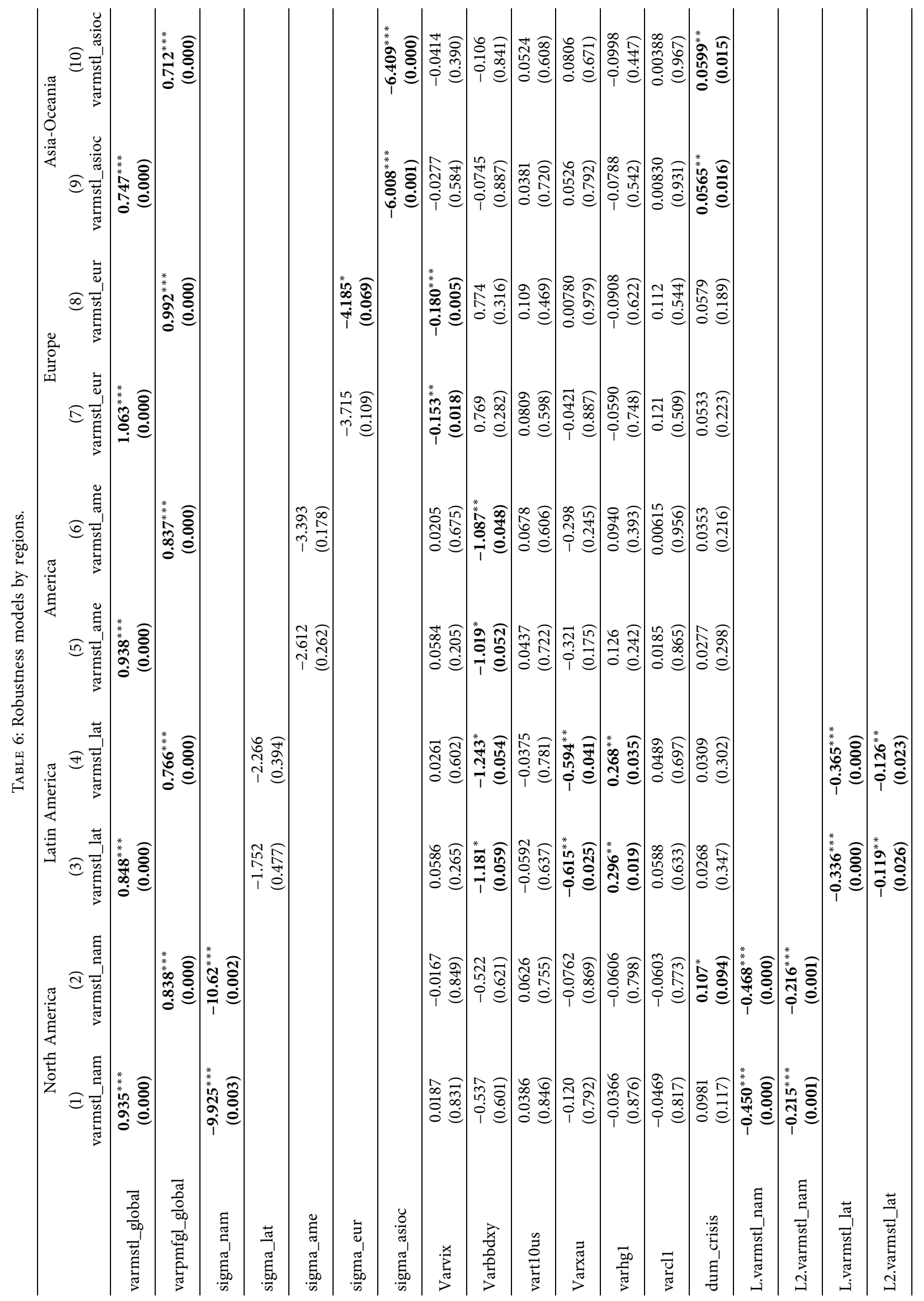




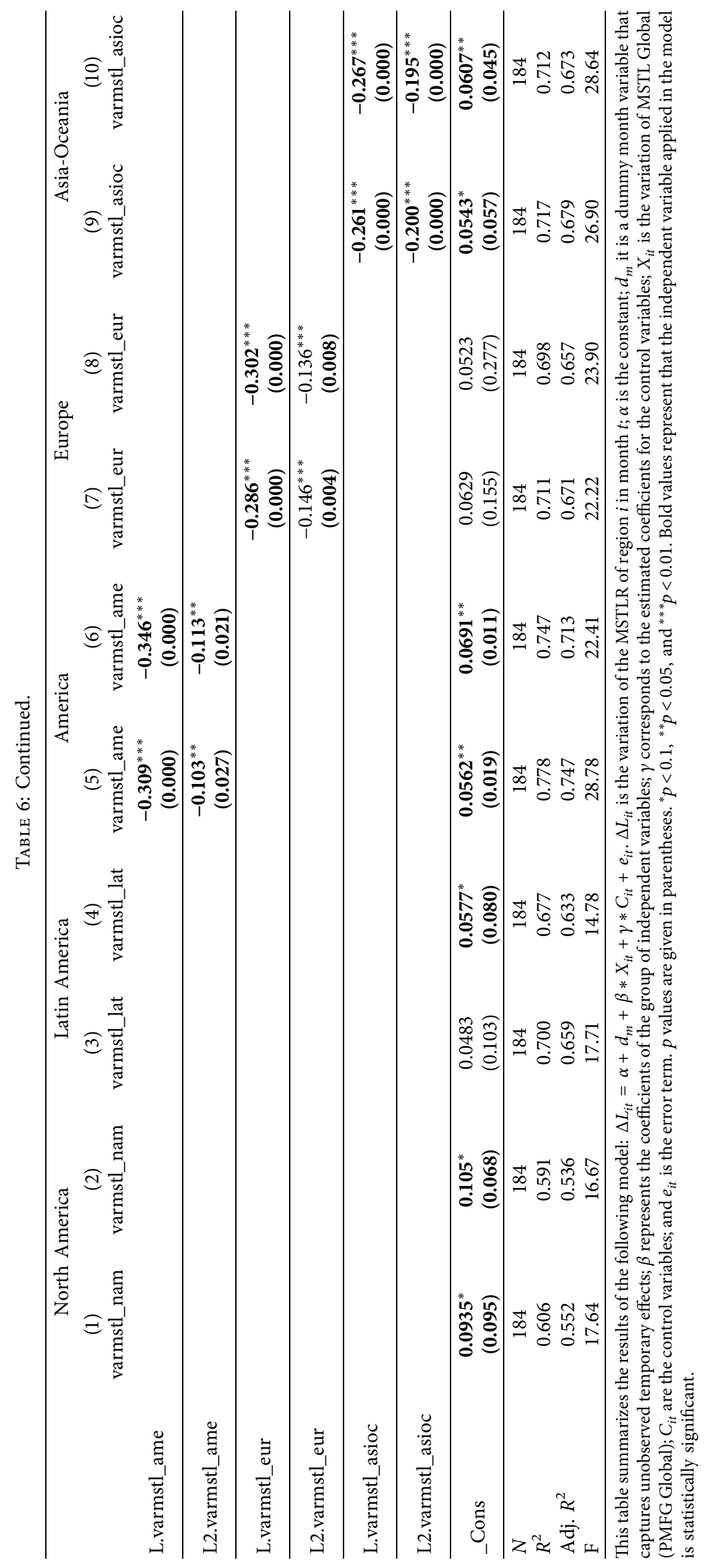




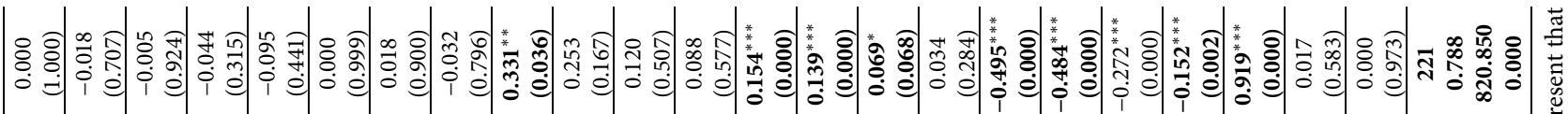
$\stackrel{\breve{\circ}}{\circ}$

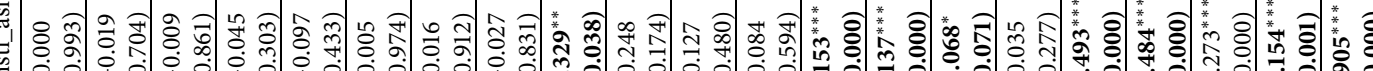

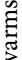

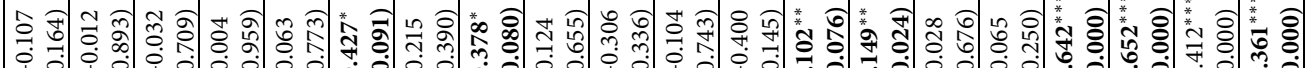
$i$ i $\sin$

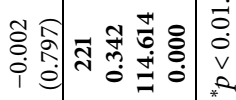

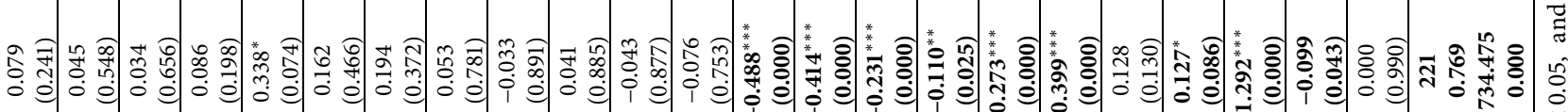

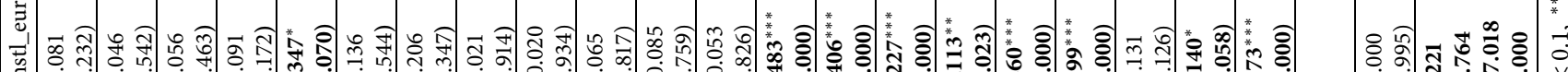

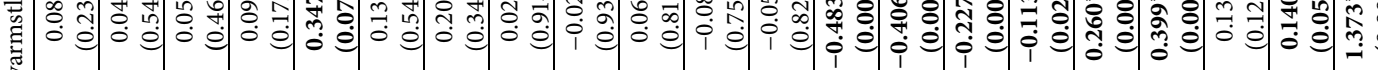

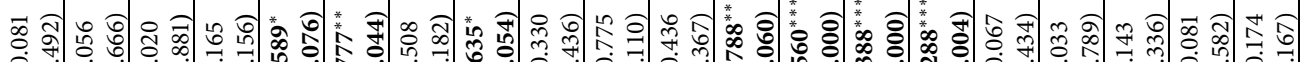

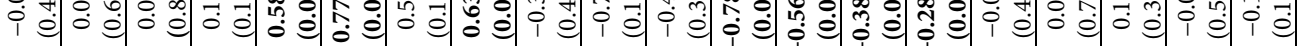

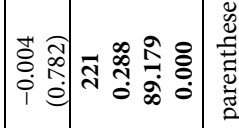

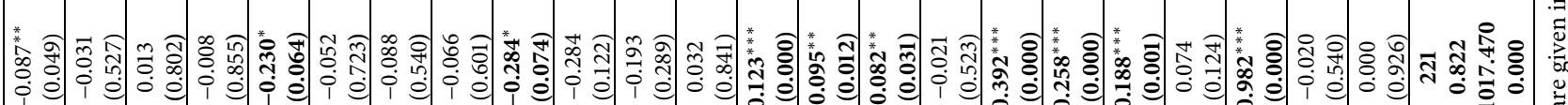

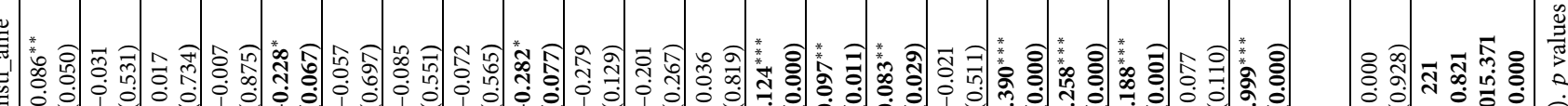

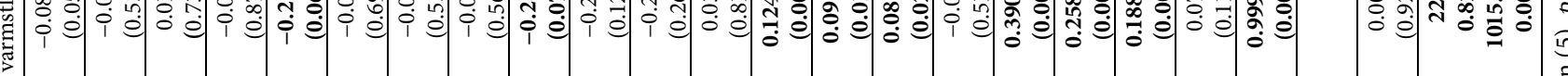

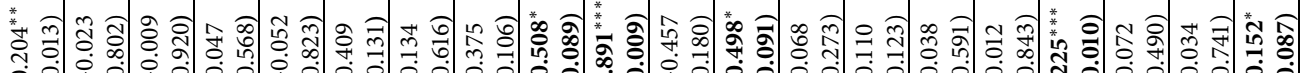

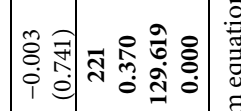

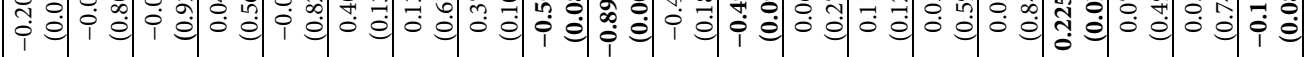

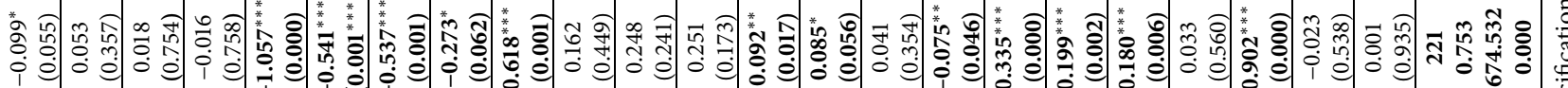

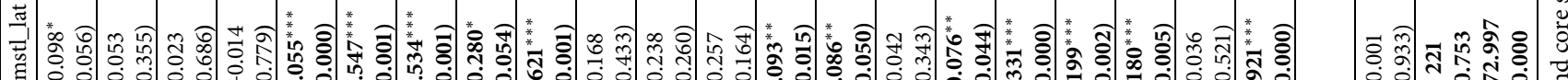

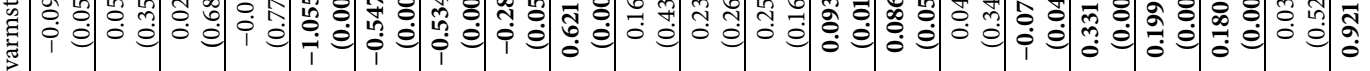

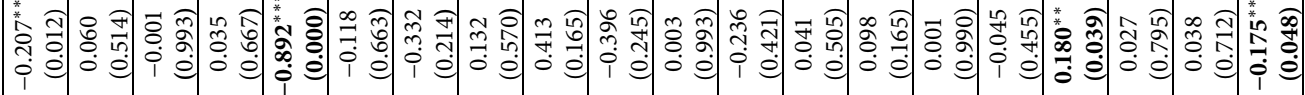

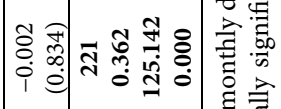

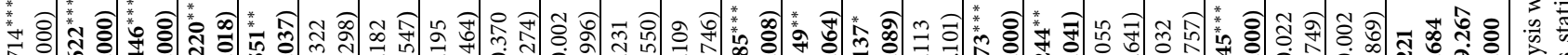

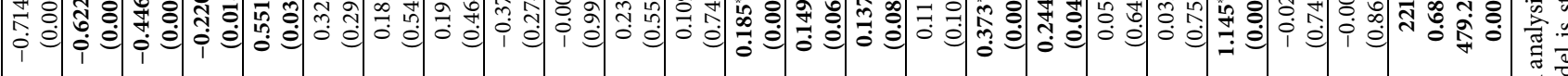

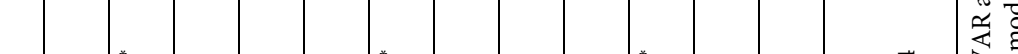

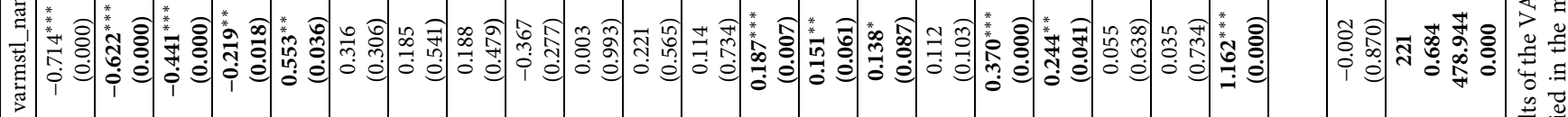

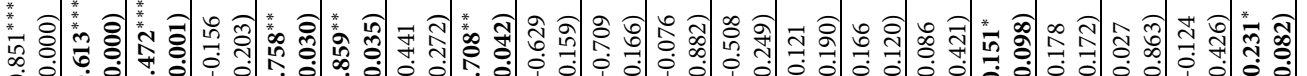
管

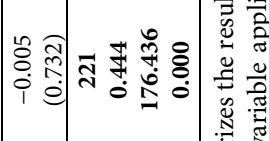

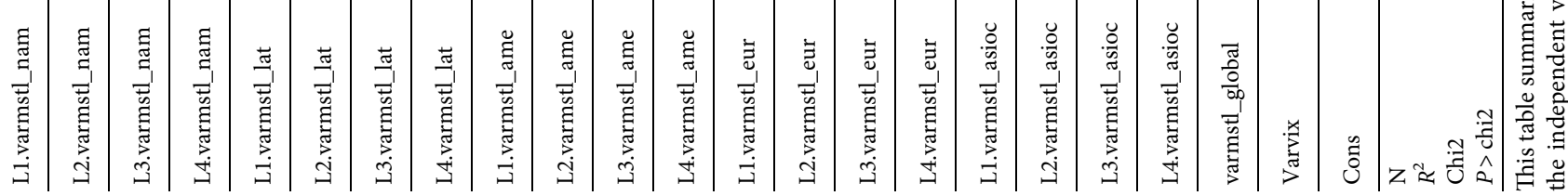



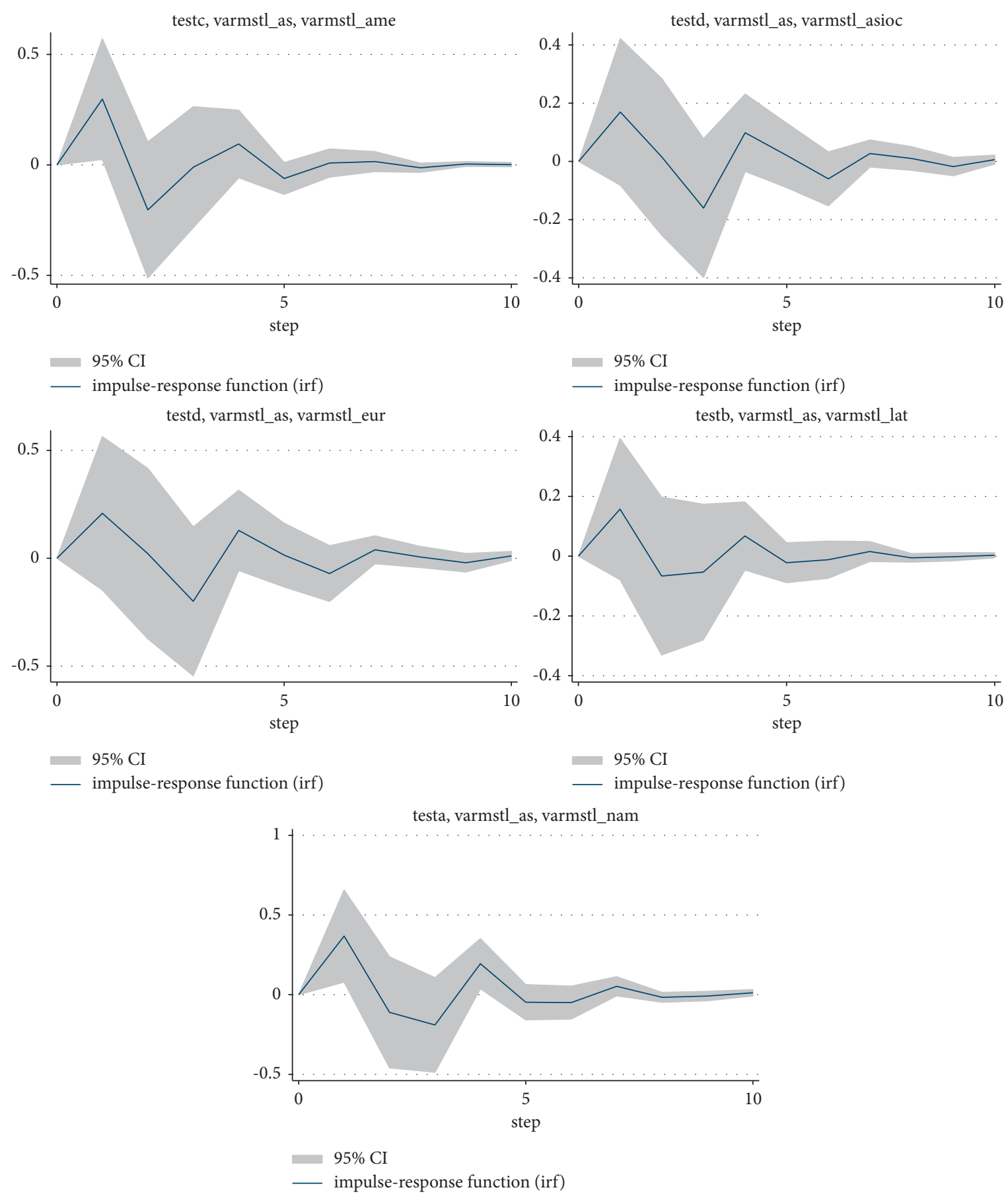

FIgURE 4: Impulse-response graphs. This figure depicts the impulse-response exercise from a shock in the global MSTL (varmstl_global) over the MSTL of North America (varmstl_nam), Latin America (varmstl_lat), America (varmstl_ame), Europe (varmstl_eur), and AsiaOceania (varmstl_asioc).

rows for the lagged dependent variables and the exogenous variables.

The main results indicate relevant mutual influence in terms of synchronization of returns among regional markets. Asia and Oceania influence all the rest regions and itself; meanwhile, North America mainly affects itself and Latin America. Concerning the impact of the global synchronization over the regional markets, our evidence confirms a direct relationship between global synchronization captured by the variable varmstl_global and the synchronization exhibited by each regional market. Moreover, these results are robust when we control from possible effects derived by changes in the implied volatility that VIX captures.

In addition, to study the length of the synchronization episodes, we perform structural VAR analysis to capture the response after a shock of one standard deviation in the global MSTL. Figure 4 shows the impulse-response functions for each region. Consistent with our previous findings, we can 


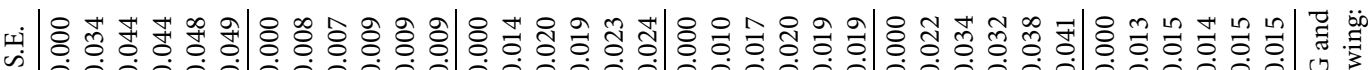

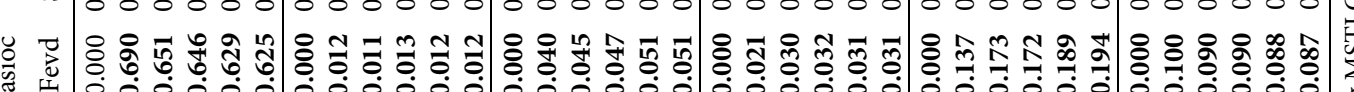

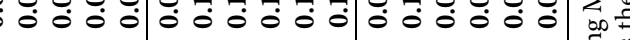

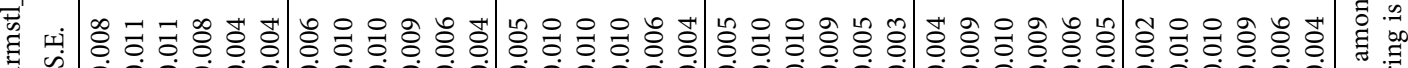

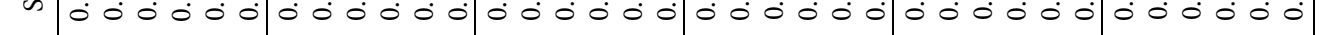

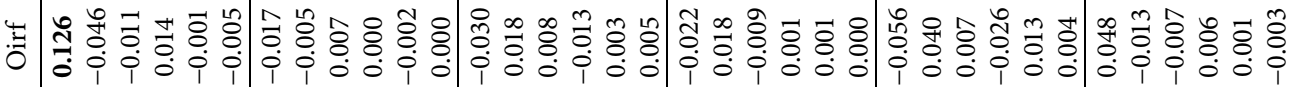

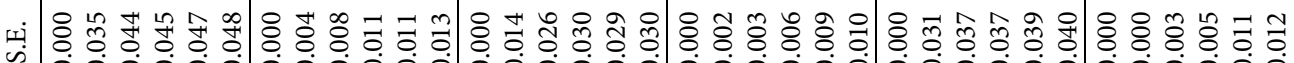

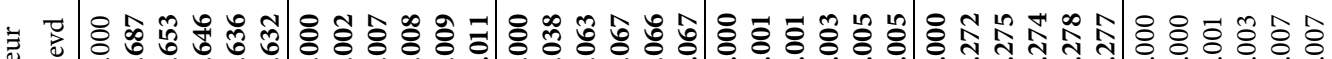
元 我

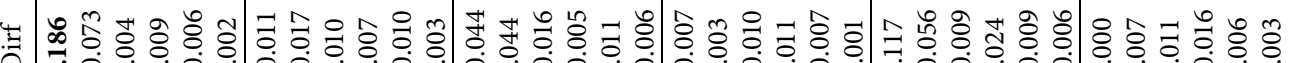
o फ

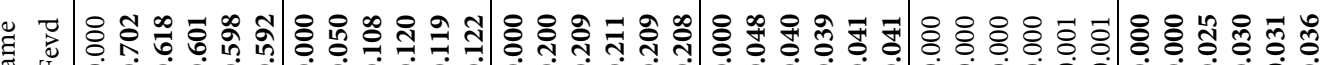

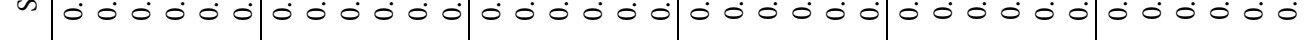

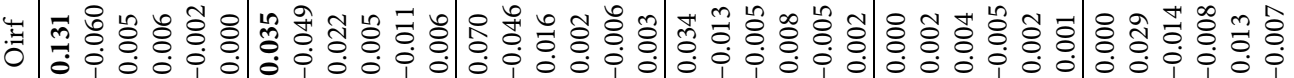

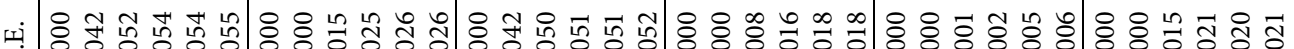

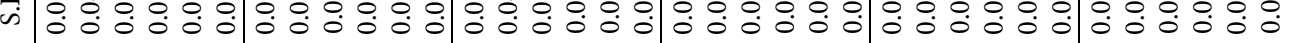

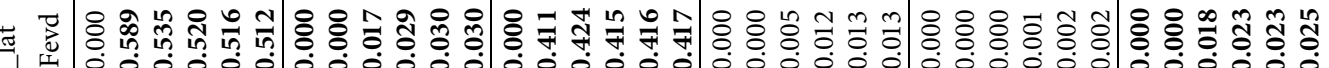
青

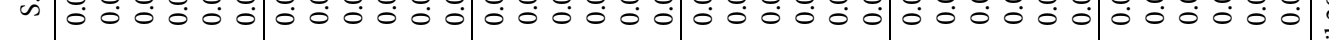

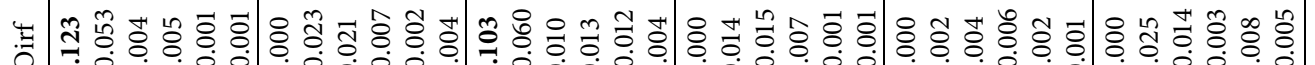

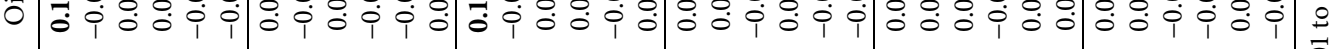

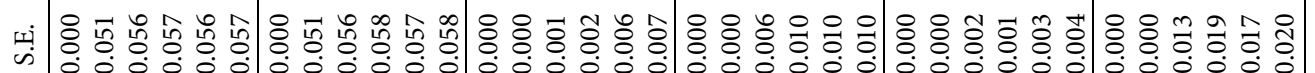
芒

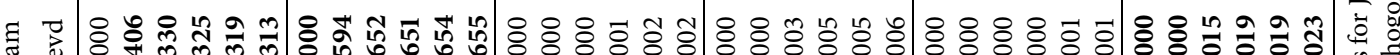
吾 苟

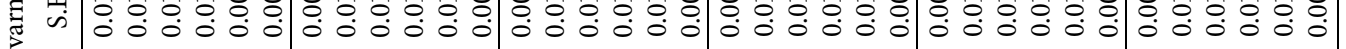

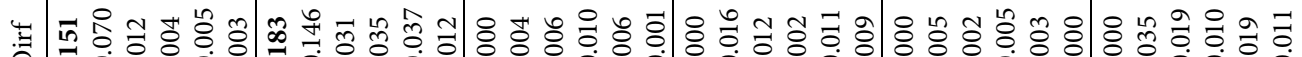
要

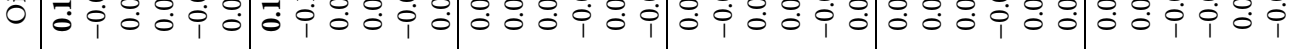

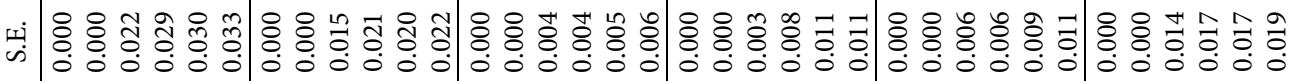

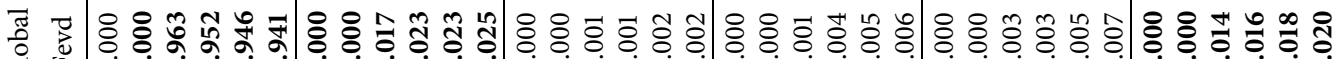
का w 羍 药 o

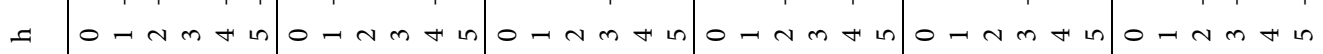
$\stackrel{\mathscr{\nu}}{\circ}$

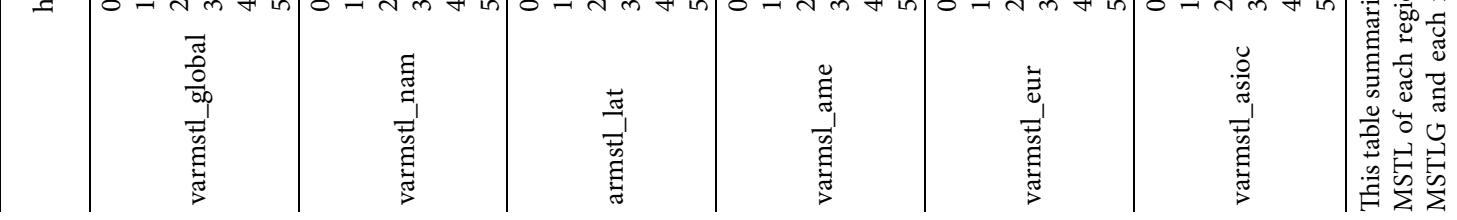


TABLE 9: Total influence of global synchronization network.

Panel A: 1-month-ahead forecast-error variance decomposition

varmstl_as varmstl_nam varmstl_lat varmstl_ame varmstl_eur varmstl_asioc Total Contribution

from others

\begin{tabular}{lcccccccc}
\hline varmstl_as & 1 & 0 & 0 & 0 & 0 & 0 & - & 0 \\
varmstl_nam & 0.406 & 0.594 & 0 & 0 & 0 & 0 & - & 0.406 \\
varmstl_lat & 0.589 & 0 & 0.411 & 0 & 0 & 0 & - & 0.589 \\
varmsl_ame & 0.702 & 0.05 & 0.2 & 0.048 & 0 & 0.952 \\
varmstl_eur & 0.687 & 0.002 & 0.038 & 0.001 & 0.272 & 0 & - & 0.728 \\
varmstl_asioc & 0.69 & 0.012 & 0.04 & 0.021 & 0.137 & 0.1 & - & 0.9 \\
Contribution to others & $\mathbf{3 . 0 7 4}$ & $\mathbf{0 . 0 6 4}$ & $\mathbf{0 . 2 7 8}$ & $\mathbf{0 . 0 2 2}$ & $\mathbf{0 . 1 3 7}$ & $\mathbf{0}$ & $\mathbf{3 . 5 7 5}$ \\
Contribution including & $\mathbf{4 . 0 7 4}$ & $\mathbf{0 . 6 5 8}$ & $\mathbf{0 . 6 8 9}$ & $\mathbf{0 . 0 7}$ & $\mathbf{0 . 4 0 9}$ & $\mathbf{0 . 1}$ & $\mathbf{6 . 0 0 0}$ \\
own & & & & & & \\
\hline
\end{tabular}

Panel B: 5-month-ahead forecast-error variance decomposition

\begin{tabular}{|c|c|c|c|c|c|c|c|c|}
\hline & varmstl_as & varmstl_nam & varmstl_lat & varmstl_ame & varmstl_eur & varmstl_asioc & Total & $\begin{array}{l}\text { Contribution } \\
\text { from others }\end{array}$ \\
\hline varmstl_as & 0.941 & 0.025 & 0.002 & 0.006 & 0.007 & 0.02 & - & 0.06 \\
\hline varmstl_nam & 0.313 & 0.655 & 0.002 & 0.006 & 0.001 & 0.023 & - & 0.345 \\
\hline varmstl_lat & 0.512 & 0.03 & 0.417 & 0.013 & 0.002 & 0.025 & - & 0.582 \\
\hline varmsl_ame & 0.592 & 0.122 & 0.208 & 0.041 & 0.001 & 0.036 & - & 0.959 \\
\hline varmstl_eur & 0.632 & 0.011 & 0.067 & 0.005 & 0.277 & 0.007 & - & 0.715 \\
\hline varmstl_asioc & 0.625 & 0.012 & 0.051 & 0.031 & 0.194 & 0.087 & - & 0.913 \\
\hline Contribution to others & 2.674 & 0.2 & 0.33 & 0.061 & 0.205 & 0.111 & 3.581 & \\
\hline $\begin{array}{l}\text { Contribution including } \\
\text { own }\end{array}$ & 3.615 & 0.855 & 0.747 & 0.102 & 0.482 & 0.198 & 5.999 & \\
\hline
\end{tabular}

This table summarizes the forecast-error variance decomposition results for the period 2001-2020 as percentage points among global MSTL and MSTL of each region. The variance decomposition is based on the orthogonalized impulse-response function and Cholesky forecast-error variance decomposition. Ordering is the following: MSTLG and each regional MSTL. Source: authors' elaboration.

observe that the MSTL in each region responds positively after a positive shock in the global MSTL (i.e., they tend to rise when the global MSTL rises and vice-versa). Moreover, in all cases, this response is significant in one period after the shock. Notably, in each region, the shock starts to be absorbed after the fifth period. These results would indicate that the duration of the synchronization phenomenon among global equity markets is not a short-term lived event.

Complementing the previous analysis, we perform an error variance decomposition for the full-sample period to assess the relevance of our global synchronization measure in terms of its influence on the synchronization of the regional markets. Table 8 shows how the orthogonalized disturbances contribute to the mean squared error (MSE) in the h-periods-ahead forecasts. We can notice the following:

(1) We observe that most MSTLs tend to be very autoregressive; in each MSTL, their lags explain a relevant part of the variance in the MSE. For instance, the MSTL lag of North America explains about sixtyfive percent of the variance in the MSTL of North America; meanwhile, for markets like Europe and Asia-Oceania, the results are substantially lower.

(2) It is worth mentioning that the global MSTL explains an essential proportion of the variance in most cases. For example, for $h=5$, it ranges from $31.3 \%$ for North America to $63.2 \%$ for the case of Europe.

(3) It is interesting to indicate significant heterogeneity among regional markets in terms of their exposure to global and local factors when episodes of global synchronization occur.

Finally, following Diebold and Yilmaz [74], we quantify the total influence of global synchronization on the world regional markets. (This framework permits studying total interdependence or total spillover effects between assets of the same nature and relies on the Cholesky-factor identification of VAR that generates a variance decomposition that can be dependent on the variable ordering. As mentioned, we consider the global synchronization as an exogenous variable and the regional synchronization as dependent variables; the ordering we apply is MSTLG and each regional MSTL. In order to determine individual or directional spillover effects and analyze different asset classes, see Diebold and Yilmaz [75] and Shaikh [76]). Table 9 exhibits the variance decomposition that results from contribution to the variance of the $h$-month-ahead synchronization forecast error of region $i$ coming from innovations to synchronizations of region $j$. Panel A shows 1-month-ahead forecast-error variance decomposition. Panel $\mathrm{B}$ exhibits the same analysis for the fifth month. We can observe that 1- and 5-monthahead contribution in terms of synchronization from the global network to regional networks is $86 \%(3.074 / 3.575)$ and $75 \%(2.674 / 3.581)$, respectively. These results highlight the crucial contribution that global synchronization exerts over the synchronization of regional markets.

In summary, our robustness analysis led us to think that the results of this section are consistent with our previous regression models: 
(1) The VAR, impulse-response functions, and MSE variance decomposition suggest a Granger causality from the global MSTL to the regional MSTL

(2) This relationship is positive; i.e., more global synchronization precedes a more regional synchronization

(3) The capacity of the global MSTL to capture future episodes of synchronization seems to go beyond the own autoregressive measure of synchronization of the regional markets

\section{Conclusions}

Our research contributes to helping financial market participants in the task of measuring and monitoring synchronization risk. For this, we estimate the synchronization of global stock markets applying MST network methods to 27 world equity markets and use it as a proxy of the global synchronization phenomenon and as a factor for explaining the synchronization of the leading world regional equity markets. In the current financial context of high uncertainty, it is relevant to ask about the dynamic of the global equity market synchronization for its implications over systemic risk, especially after strong rallies in equity values after the COVID-19 outbreak when the risk of stock price corrections is higher. Therefore, the threat that novel emerging shocks affect financial markets and provoke new episodes of stock market synchronization is high.

Our main results evidence that the global equity market synchronization, measured by the length of the global MSTL (MSTLG), is dynamic over time, its minimum values coincide with relevant financial shocks, and it shrinks to its minimum levels, indicating that the returns of the global stock markets are moving in a synchronized way. Likewise, the changes in the topology of the global MST capture the impact of shocks of different natures on financial markets but have a similar impact on the assets' correlation, a behavior that finally provokes the synchronization phenomenon. In addition, our evidence indicates that global synchronization of the stock markets is a significant factor explaining the synchronization of the world regional equity markets during the last 20 years. Also, we find a positive relationship between the variations in the global synchronization of equity returns and the variations in the synchronization associated with the world regional markets. Finally, our results show different sensitivities among the regional equity markets to global equity synchronization variations.

Our evidence does not reject the hypothesis that the global synchronization of returns is a statistically significant factor in explaining the synchronization of regional markets' returns. Nevertheless, this evidence is crucial to understand the links between global and regional economic and financial factors, elements that rise due to business internationalization, lowered transaction costs, and growing international investments. This major interconnectedness and globalization are suitable for the development of the economies. However, in times of market turmoil, it can become a significant problem since the considerable increase in the synchronization of returns diminishes portfolio diversification's benefits and becomes an element of contagion.

In addition, we cannot reject the hypothesis that there are statistically significant differences among regional markets with the degree of sensitivity to the global synchronization of returns. On the contrary, we find a positive relationship between both variables, which suggests that when the global synchronization increases, the regional synchronization will increase too, and vice-versa. In conclusion, our results support the idea that the complex and interconnected nature of the present financial markets should motivate practitioners and regulators to revise and update beliefs regarding risk management to incorporate monitoring and management of the risk of synchronization as a priority.

Our research does not analyze the structural links between global and regional markets in terms of market synchronizations' spillover. Instead, we evaluate the impact of the global synchronization of stock returns on world regional markets and their sensitivity to this factor applying Pearson correlation-based network methods. A natural extension of our work relates to exploring the application of other networks methods, such as partial correlation networks $[35,74]$ in relevant assets in terms of assets under management (AUM) like bonds, commodities, and real estate, considering different economic sectors in both developed and developing countries. As well, it is a relevant deeper study using Pearson and partial correlation-based networks of the synchronization spillovers that arise due to structural interconnectedness present among different markets in terms of asset classes, regions, and sectors in order to gain a deeper understanding of the directional spillover inherent among financial assets and markets and their impact on systemic risk $[75,76]$.

One limitation of our study is the impact of the nonsynchronous trading effect (i.e., time zone differences) on global stock markets. Our focus is not to solve this problem because there is still no efficient way to deal with this problem [35]. Unfortunately, the option of working with weekly frequencies to eliminate the nonsynchronous trading effect causes the loss of valuable information on the daily activity of the markets as a problem. Nevertheless, this problem is more significant in the global MSTL series due to time zone differences, while in the regional MSTL series, this problem tends to be minimized. However, we conjecture that the nonsynchronous trading effect would tend to decrease when working with the first differences (variation of the global MSTL) and even more when estimating the coefficient of relationship between the variation of the global MSTL with the regional MSTL variations. Furthermore, Forbes and Rigobon [77] did not observe differences when implementing heteroscedasticity bias tests for contagion based on correlation coefficients using 2-day moving average correlation estimation windows and daily returns. Therefore, we believe it is necessary for future research to analyze potential methodological modifications that tackle the nonsynchronous trading effect. 
Our work has many implications. First, it helps regulators, central banks, policy-makers, portfolio managers, and investors to measure, monitor, and manage the synchronization of returns. Second, as the benefits of international diversification diminishes when synchronization rises, risk management strategies founded on investing abroad require a revisit that incorporates this risk on the decision-making criteria. Third, global financial agents, such as investment banks, must innovate and develop new financial engineering products that help market participants to manage synchronization risk. Finally, markets regulators and policy-makers, as well as central banks and governments, need to incorporate these new perspectives and insights based on empirical evidence as input factors that conduct them to supervise the wellfunctioning of financial markets better, as well as to improve the coordination of the financial market before emerging global shocks again jeopardize the stability of capital markets.

\section{Data Availability}

The data used to support the findings of this study are available from the corresponding author upon request.

\section{Additional Points}

(i) Using correlation-based network methods, such as minimum spanning trees (MSTs) and Planar Maximally Filtered Graphs (PMFGs), we study the impact of global synchronization of equity returns on the world equity markets of North America, Latin America, Europe, Asia, and Oceania. For this, we estimate the length of the MST and PMFG as a measure for the global synchronization phenomena using daily and monthly data between July 2001 and April 2020.

(ii) Our results evidence that the global synchronization of equity markets, measured by the length of the global MSTL, is dynamic over time, its minimum values coincide with relevant financial shocks, and it shrinks to its minimum levels, indicating that the global returns are moving in a synchronized way. Likewise, the changes in the topology of the global MST rightly capture the impact of shocks of different natures on financial markets, but that have a similar impact on the assets' correlation in terms of synchronization.

(iii) Using time-series regression analysis and structural VAR models, we find that the global synchronization of equity returns has a significant and positive impact on the contemporaneous and future synchronization of the world regional equity markets. Also, the reaction of the regional synchronization is unequal to variations in global synchronization levels. We find a wide heterogeneity response among regional markets to shocks in global synchronization levels. (iv) Our results help financial market participants who need to measure, monitor, and manage the synchronization of returns. Likewise, our evidence shows the necessity of including synchronization as a risk factor to assess the decision-making criteria to policy-makers and regulators. Our work highlights the need to incorporate events of high global synchronization into the radar of hazards of market stability.

\section{Conflicts of Interest}

The authors declare that they have no conflicts of interest.

\section{Acknowledgments}

The authors would like to thank Universidad Adolfo Ibáñez under Internal Funds for Research 2020-2022 grant (Business School-1154-2020) for financially supporting this research.

\section{References}

[1] M. Billio, M. Getmansky, A. W. Lo, and L. Pelizzon, "Econometric measures of connectedness and systemic risk in the finance and insurance sectors," Journal of Financial Economics, vol. 104, no. 3, pp. 535-559, 2012.

[2] P. Gai, A. Haldane, and S. Kapadia, "Complexity, concentration and contagion," Journal of Monetary Economics, vol. 58, no. 5, pp. 453-470, 2011.

[3] A. G. Haldane, "Rethinking the financial network," Fragile Stabilität-Stabile Fragilität, Springer VS, Wiesbaden, Germany, pp. 243-278, 2013.

[4] N. Antonakakis, I. Chatziantoniou, and G. Filis, "Dynamic comovements of stock market returns, implied volatility and policy uncertainty," Economics Letters, vol. 120, no. 1, pp. 87-92, 2013.

[5] P. Glasserman and H. P. Young, "Contagion in financial networks," Journal of Economic Literature, vol. 54, no. 3, pp. 779-831, 2016.

[6] M. Summer, "Financial contagion and network analysis," Annual Review of Financial Economics, vol. 5, no. 1, pp. 277-297, 2013.

[7] S. Benoit, J.-E. Colliard, C. Hurlin, and C. Pérignon, "Where the risks lie: a survey on systemic risk"," Review of Finance, vol. 21, no. 1, pp. 109-152, 2017.

[8] N. S. Magner, J. F. Lavin, M. A. Valle, and N. Hardy, "The volatility forecasting power of financial network analysis," Complexity, vol. 2020, Article ID 7051402, 17 pages, 2020.

[9] M. Raddant and D. Y. Kenett, "Interconnectedness in the global financial market," Journal of International Money and Finance, vol. 110, Article ID 102280, 2021.

[10] A. Lahrech and K. Sylwester, "U.S. and Latin American stock market linkages," Journal of International Money and Finance, vol. 30, no. 7, pp. 1341-1357, 2011.

[11] R. Greenwood, A. Landier, and D. Thesmar, "Vulnerable banks," Journal of Financial Economics, vol. 115, no. 3, pp. 471-485, 2015.

[12] M. Elliott, B. Golub, and M. O. Jackson, "Financial networks and contagion," The American Economic Review, vol. 104, no. 10, pp. 3115-3153, 2014.

[13] J. F. Lavin, M. A. Valle, and N. S. Magner, "Modeling overlapped mutual funds' portfolios: a bipartite network 
approach," Complexity, vol. 2019, Article ID 1565698, 20 pages, 2019.

[14] N.-Z. Guo and A. H. Tu, "Stock market synchronization and institutional distance," Finance Research Letters, vol. 42, Article ID 101934, 2021.

[15] S. Wälti, "Stock market synchronization and monetary integration," Journal of International Money and Finance, vol. 30, no. 1, pp. 96-110, 2011.

[16] D.-M. Song, M. Tumminello, W.-X. Zhou, and R. N. Mantegna, "Evolution of worldwide stock markets, correlation structure, and correlation-based graphs," Physical Review E, vol. 84, no. 2, 2011.

[17] T. Výrost, Š. Lyócsa, and E. Baumöhl, "Network-based asset allocation strategies," The North American Journal of Economics and Finance, vol. 47, pp. 516-536, 2019.

[18] R. Engle and B. Kelly, "Dynamic equicorrelation," Journal of Business \& Economic Statistics, vol. 30, no. 2, pp. 212-228, 2012.

[19] T. Adrian and M. K. Brunnermeier, "CoVaR," The American Economic Review, vol. 106, no. 7, pp. 1705-1741, 2016.

[20] A. Krause and S. Giansante, "Interbank lending and the spread of bank failures: a network model of systemic risk," Journal of Economic Behavior \& Organization, vol. 83, no. 3, pp. 583-608, 2012.

[21] V. Acharya, R. Engle, and M. Richardson, "Capital shortfall: a new approach to ranking and regulating systemic risks," American Economic Review, vol. 102, no. 3, pp. 59-64, 2012.

[22] V. V. Acharya, L. H. Pedersen, T. Philippon, and M. Richardson, "Measuring systemic risk," Review of Financial Studies, vol. 30, no. 1, pp. 2-47, 2017.

[23] X. Huang, H. Zhou, and H. Zhu, "A framework for assessing the systemic risk of major financial institutions," Journal of Banking \& Finance, vol. 33, no. 11, pp. 2036-2049, 2009.

[24] D. Acemoglu, A. Ozdaglar, and A. Tahbaz-Salehi, "Systemic risk and stability in financial networks," The American Economic Review, vol. 105, no. 2, pp. 564-608, 2015.

[25] N. Kiyotaki and J. Moore, "Credit cycles," Journal of Political Economy, vol. 105, no. 2, pp. 211-248, 1997.

[26] F. Allen and D. Gale, "Financial contagion," Journal of Political Economy, vol. 108, no. 1, pp. 1-33, 2000.

[27] R. Albert, H. Jeong, and A.-L. Barabási, "Error and attack tolerance of complex networks," Nature, vol. 406, no. 6794, pp. $378-382,2000$.

[28] A. G. H. A. G. Haldane, The Dog and the FrisbeeBank of England, London, UK, 2012.

[29] R. N. Mantegna, "Hierarchical structure in financial markets," The European Physical Journal B, vol. 11, no. 1, pp. 193-197, 1999.

[30] R. N. Mantegna and H. E. Stanley, Introduction to Econophysics, 1999.

[31] J.-P. Onnela, A. Chakraborti, K. Kaski, J. Kertész, and A. Kanto, "Dynamics of market correlations: taxonomy and portfolio analysis," Physical Review E, vol. 68, no. 5, 2003.

[32] J. Eberhard, J. F. Lavin, and A Montecinos-pearce, "A network-based dynamic analysis in an equity stock market," Complexity, vol. 2017, Article ID 3979836, 16 pages, 2017.

[33] M. Tumminello, T. Aste, T. Di Matteo, and R. N. Mantegna, "A tool for filtering information in complex systems," Proceedings of the National Academy of Sciences, vol. 102, no. 30, pp. 10421-10426, 2005.

[34] J.-P. Onnela, K. Kaski, and J. Kertsz, "Clustering and information in correlation based financial networks," The European Physical Journal B (EPJ B)-Condensed Matter, vol. 38, no. 2, pp. 353-362, 2004.
[35] G.-J. Wang, C. Xie, and H. E. Stanley, "Correlation structure and evolution of world stock markets: evidence from Pearson and partial correlation-based networks," Computational Economics, vol. 51, no. 3, pp. 607-635, 2016.

[36] W. Li, U. Hommel, and S. Paterlini, "Network topology and systemic risk: evidence from the Euro Stoxx market," Finance Research Letters, vol. 27, pp. 105-112, 2018.

[37] T. Výrost, Š. Lyócsa, and E. Baumöhl, "Granger causality stock market networks: temporal proximity and preferential attachment," Physica A: Statistical Mechanics and Its Applications, vol. 427, pp. 262-276, 2015.

[38] G.-J. Wang, C. Xie, K. He, and H. E. Stanley, "Extreme risk spillover network: application to financial institutions," Quantitative Finance, vol. 17, no. 9, pp. 1417-1433, 2017.

[39] F. X. Diebold and K. Yilmaz, "On the network topology of variance decompositions: measuring the connectedness of financial firms," Journal of Econometrics, vol. 182, no. 1, pp. 119-134, 2014.

[40] X. Liu, H. An, H. Li, Z. Chen, S. Feng, and S. Wen, "Features of spillover networks in international financial markets: evidence from the G20 countries," Physica A: Statistical Mechanics and Its Applications, vol. 479, pp. 265-278, 2017.

[41] N. Hautsch, J. Schaumburg, and M. Schienle, "Financial network systemic risk contributions," Review of Finance, vol. 19, no. 2, pp. 685-738, 2015.

[42] W. K. Härdle, W. Wang, and L. Yu, "Tenet: tail-event driven network risk," Journal of Econometrics, vol. 192, no. 2, pp. 499-513, 2016.

[43] W. Zhang, X. Zhuang, J. Wang, and Y. Lu, "Connectedness and systemic risk spillovers analysis of Chinese sectors based on tail risk network," The North American Journal of Economics and Finance, vol. 54, Article ID 101248, 2020.

[44] G. Peralta and A. Zareei, "A network approach to portfolio selection,” Journal of Empirical Finance, vol. 38, pp. 157-180, 2016.

[45] J. Cai, F. Eidam, A. Saunders, and S. Steffen, "Syndication, interconnectedness, and systemic risk," Journal of Financial Stability, vol. 34, pp. 105-120, 2018.

[46] T. Bury, "Market structure explained by pairwise interactions," Physica A: Statistical Mechanics and Its Applications, vol. 392, no. 6, pp. 1375-1385, 2013.

[47] L. Zhao, W. Li, and X. Cai, "Structure and dynamics of stock market in times of crisis," Physics Letters A, vol. 380, no. 5-6, pp. 654-666, 2016.

[48] H. L. Gao and D. C. Mei, "The correlation structure in the international stock markets during global financial crisis," Physica A: Statistical Mechanics and its Applications, vol. 534, 2019.

[49] W.-S. Jung, S. Chae, J.-S. Yang, and H.-T. Moon, "Characteristics of the Korean stock market correlations," Physica A: Statistical Mechanics and its Applications, vol. 361, no. 1, pp. 263-271, 2006.

[50] G. Bonanno, G. Caldarelli, F. Lillo, and R. N. Mantegna, "Topology of correlation-based minimal spanning trees in real and model markets," Physical Review E, vol. 68, no. 4, Article ID 46130, 2003.

[51] T. K. Dal'Maso Peron and F. A. Rodrigues, "Collective behavior in financial markets," EPL (Europhysics Letters), vol. 96, no. 4, p. 48004, 2011.

[52] N. Nakagawa and Y. Kuramoto, "From collective oscillations to collective chaos in a globally coupled oscillator system," Physica D: Nonlinear Phenomena, vol. 75, no. 1-3, pp. 74-80, 1994. 
[53] R. V. Donner, Y. Zou, J. F. Donges, N. Marwan, and J. Kurths, "Recurrence networks-a novel paradigm for nonlinear time series analysis," New Journal of Physics, vol. 12, no. 3, Article ID 33025, 2010.

[54] N. Marwan, M. Carmenromano, M. Thiel, and J. Kurths, "Recurrence plots for the analysis of complex systems," Physics Reports, vol. 438, no. 5-6, pp. 237-329, 2007.

[55] A. Sensoy, D. K. Nguyen, A. Rostom, and E. Hacihasanoglu, "Dynamic integration and network structure of the EMU sovereign bond markets," Annals of Operations Research, vol. 281, no. 1-2, pp. 297-314, 2019.

[56] R. Roll, "Industrial structure and the comparative behavior of international stock market indices," The Journal of Finance, vol. 47, no. 1, pp. 3-41, 1992.

[57] E. H. Chow, W. Y. Lee, and M. E. Solt, "The exchange-rate risk exposure of asset returns," Journal of Business, vol. 70, no. 1, p. 105, 1997.

[58] K. Phylaktis and F. Ravazzolo, "Stock prices and exchange rate dynamics," Journal of International Money and Finance, vol. 24, no. 7, pp. 1031-1053, 2005.

[59] C. Ciner, C. Gurdgiev, and B. M. Lucey, "Hedges and safe havens: an examination of stocks, bonds, gold, oil and exchange rates," International Review of Financial Analysis, vol. 29, pp. 202-211, 2013.

[60] J. P. Onnela, A. Chakraborti, K. Kaski, and J. Kertész, "Dynamic asset trees and black monday," 2003, https://arxiv.org/ abs/cond-mat/0212037.

[61] T. Araújo and F. Louçã, "The geometry of crashes. A measure of the dynamics of stock market crises," Quantitative Finance, vol. 7, no. 1, pp. 63-74, 2007.

[62] R. C. Prim, "Shortest connection networks and some generalizations," Bell System Technical Journal, vol. 36, no. 6, pp. 1389-1401, 1957.

[63] M. Eryiğit and R. Eryiğit, "Network structure of cross-correlations among the world market indices," Physica A: Statistical Mechanics and Its Applications, vol. 388, no. 17, pp. 3551-3562, 2009.

[64] S. Lyócsa, T. Výrost, and E. Baumöhl, "Stock market networks: the dynamic conditional correlation approach," Physica A: Statistical Mechanics and Its Applications, vol. 391, no. 16, pp. 4147-4158, 2012.

[65] D. A. Dickey and W. A. Fuller, "Distribution of the estimators for autoregressive time series with a unit root," Journal of the American Statistical Association, vol. 74, no. 366, p. 427, 1979.

[66] P. C. B. Phillips and P. Perron, "Testing for a unit root in time series regression," Biometrika, vol. 75, no. 2, pp. 335-346, 1988.

[67] D. K. Nguyen, R. M. Sousa, and G. S. Uddin, "Testing for asymmetric causality between U.S. equity returns and commodity futures returns," Finance Research Letters, vol. 12, pp. 38-47, 2015.

[68] R. J. Shiller and A. E. Beltratti, "Stock prices and bond yields: Can their comovements be explained in terms of present value models," Journal of Monetary Economics, vol. 30, no. 1, pp. 25-46, 1992.

[69] J. Park and R. A. Ratti, "Oil price shocks and stock markets in the U.S. and 13 European countries," Energy Economics, vol. 30, no. 5, pp. 2587-2608, 2008.

[70] N. Apergis and S. M. Miller, "Do structural oil-market shocks affect stock prices?" Energy Economics, vol. 31, no. 4, pp. 569-575, 2009.

[71] P. S. Banerjee, J. S. Doran, and D. R. Peterson, "Implied volatility and future portfolio returns," Journal of Banking \& Finance, vol. 31, no. 10, pp. 3183-3199, 2007.
[72] J. Birch, A. A. Pantelous, and K. Soramäki, "Analysis of correlation based networks representing DAX 30 stock price returns," Computational Economics, vol. 47, no. 4, pp. 501-525, 2016.

[73] Z. Yang and Y. Zhou, "Quantitative easing and volatility spillovers across countries and asset classes," Management Science, vol. 63, no. 2, pp. 333-354, 2017.

[74] R. N. Mantegna and H. E. Stanley, An Introduction to Econophysics: Correlations and Complexity in Finance, Cambridge University Press, Cambridge, UK, 2000.

[75] F. X. Diebold and K. Yilmaz, "Better to give than to receive: predictive directional measurement of volatility spillovers," International Journal of Forecasting, vol. 28, no. 1, pp. 57-66, 2012.

[76] I. Shaikh, "Impact of COVID-19 pandemic disease outbreak on the global equity markets," Economic Research-Ekonomska Istraživanja, vol. 34, no. 1, pp. 2317-2336, 2021, http://www. tandfonline.com/action/authorSubmission?journalCode $=$ rero20\& page=instructions 2020 .

[77] K. J. Forbes and R. Rigobon, "No contagion, only interdependence: measuring stock market comovements," The Journal of Finance, vol. 57, no. 5, pp. 2223-2261, 2002. 